\title{
Measuring Internationality Of Board Members via Secondary Data - A Comparison Of Methods
}

Lutz Sommer, Albstadt-Sigmaringen University, Germany

\begin{abstract}
The assessment of the internationality of board members is based on the quality of the assessment of each individual member. In practice, different indices based on secondary data are used to capture the internationality of management boards. The CVs of 213 board members of DAX-listed companies were analyzed with regard to internationally relevant data with the aim to compare the quality of the refined benchmark index InEx ${ }_{N W E+W E}$ P to a selection of indices used in practice in terms of their information value. The results show that the partly very simplistic indices used in practice lead to significant distortions with regard to the assessment of the internationality of individual board members and thus of the management boards as whole. In other words, the simpler indices don't use the information potential of the existing secondary data sufficiently, thus enticing the viewer to partly significant misinterpretations.
\end{abstract}

Keywords: Internationality; Board Members

\section{INTRODUCTION}

$\mathrm{n}$ the face of a globalizing environment, the internationalization of enterprises is widely regarded as a logical conclusion. The management board of an enterprise can be considered as an important parameter for corporate success. The importance of management boards in the context of the internationalization of enterprises has already been discussed early on in literature (Ghoshal, 1987). Tushman and Nadler (1978), as well, referred to the need for appropriate structures to meet the challenges of the international market. With regard to management boards, extensive studies on the subject of "Top Management Teams (TMT)" have been conducted since the mid-eighties (Heijltjes \& Olie \& Glunk, 2003, p. 89). The work of Hambrick and Mason (1984) which resulted in the "upper echelons theory" approach was of paramount importance. According to the authors, international experience is a key competence of managers when it comes to a company's success in an international environment.

This view is consistent with several other studies in recent years (cf. Carpenter \& Sanders \& Gregersen, 2001; Harrison \& Klein, 2007). However, the wide agreement in literature about the importance of international experience (IE) of, for example, board members must not hide the fact that with regard to measuring internationality there are no standardized measuring instruments, as the remarks below will show. In addition to the measuring as such, a second problem is that very often primary data (for example from interviews) are not available and that the available secondary data (for example published resumes) are often incomplete, in need of interpretation or even contradictory. In the absence of primary data, it is in practice very often inevitable to resort to secondary data, thus tacitly accepting major errors. If these errors are tolerated, the question arises of how to summarize the existing data to an index with a high information value. To this end, there were different approaches both with a more theoretical and a practical background which will be shown below. Publications of various consulting firms and foundations have shown that there exists a demand for such indices in practice. An example of the involvement of International Experience as part of corporate governance considerations is provided by the consulting firm Heidrick and Struggles Consulting (2011) who illustrate the "state of corporate governance in Europe" by six key areas (Heidrick \& Struggles Consulting, 2011, pp. 4 et seqq.): 1. availability / 2. transparency / 3. competitiveness of remuneration / 4. 
evaluation / 5. independence / 6. diversity of experience. The aspect "diversity of experience" is described as follows: " $\ldots$ is made up of 12 criteria. Some of them measure tangible aspects of diversity (e.g. nationalities on the board, diversity of background, CEO representation) while others look at the potential for change in the boardroom" (Heidrick \& Struggles Consulting, 2011, p. 5). Another example of the practical relevance of measuring international experience is provided by the consulting firm Simon Kucher \& Partners which has been collecting data on the internationality of board members of DAX-listed companies for more than ten years. The analysis reveals an increase in the internationality of DAX board members from 13.3 percent in 2000 to 27.8 percent in 2011 that is, an increase of 14.5 percent (Simon Kucher \& Partners, 2011). The determination of internationality is based on an index that measures the share of foreign board members. Similar studies are conducted by other well-known consulting firms, too, as for example Spencer Stuart with the Spencer Stuart Board Index (Spencer Stuart Consulting, 2010; Spencer Stuart Consulting, 2011) or Egon Zehnder with the Global Board Index (Egon Zehnder International, 2008). In addition to the more practical approaches which tried to use simplifications to present the facts clearly there are also studies which prefer a more complex index structure. This includes the study of Schmid and Daniel (2006) who have chosen a holistic approach. The authors have commented on this as follows: “...we will select four important indicators of board internationalization and we will present three different ways of combining them in one index" (Schmid \& Daniel, 2006, p. 1). The selected methods for measuring the internationality of management boards vary considerably in terms of complexity, measurement methodology and statement so that on the one hand a comparative analysis seems to be useful, but on the other hand there is also room for the generation of a new index. Literature offers a variety of approaches/interpretations of what can be understood by International Experience (IE) and how it can possibly be detected. The following table offers an overview (Schmid \& Kretschmer, 2005, p. 8):

Table 1 International Experience - Different manifestations

\begin{tabular}{lll}
\hline No. & \multicolumn{1}{c}{ Sources of "International Experience" } & \multicolumn{1}{c}{ Source } \\
\hline 1 & International assignments & Sullivan (1994); Roth (1995); Sambarya \\
& & (1996); Daily \& Certo \& Dalton (2000); \\
Carpenter \& Fredrickson (2001) & \\
2 & $\begin{array}{l}\text { Experience in an international function or function with international } \\
\text { responsibility }\end{array}$ & Roth (1995) \\
3 & Experience in an international division & Sambarya (1996); Herrmann \& Datta (2002) \\
4 & International work experience & Bloodgood \& Sapienza \& Almeida (1996); \\
& & Tihany\&Ellstrand \& Daily \& Dalton (2000); \\
& & Carpenter \& Pollock \& Leary (2003); \\
& & Schmid \& Kretschmer (2005); Takeuchi \& \\
& & Tesluk \& Lepak(2005); Lee \& Sukoco \\
5 & International schooling & (2007) \\
6 & Work experience abroad & Bloodgood \& Sapienza \& Almeida (1996) \\
7 & International sales experience & Reuber \& Fischer (1997) \\
8 & International education & Reuber \& Fischer (1997) \\
& & Tihany et al. (2000) ; Herrmann \& Datta \\
9 & Responsibility for an international department (or work abroad) & (2002); Carpenter et al. (2003); Schmid \& \\
10 & Career international functional business experience & Kretschmer (2005) \\
11 & Experience in eight geographic regions & Wally \& Becerra (2001) \\
12 & Foreign assignments & Athanassiou \& Nigh (2002) \\
13 & International experience diversity of TMT members & Athanassiou \& Nigh (2002) \\
14 & International non-work experience & Herrmann \& Datta (2002)
\end{tabular}

Note. Modified illustration based on Schmid and Kretschmer, 2005, p. 8

In the following, several approaches for determining the internationality of board members will be described. In the first step, the focus will be placed on internationality indices that, in practice, are published at certain time intervals.

Index according to Simon Kucher \& Partners (KP Index P): This index that has been published continuously for the past ten years by the German consulting firm Simon Kucher \& Partners, determines the internationality of the management board of a company as a whole with respect to the thirty DAX-listed companies. In the following, this 
index will be called $\mathrm{KP}_{\text {Index }}$ as the consulting firm has waived its own nomenclature or formula. The index will be established by determining the percentage rate of foreign board members relating to the total number of board members. The following formula which is in line with the general implication of Simon Kucher \& Partners (2011) could be used for measuring internationality:

$$
\mathrm{KP}_{\text {Index }}=\frac{\text { number of foreign board members of a company }}{\text { total number of board members of a company }}
$$

For 2011, the consulting firm detected a share of foreign board members of 27.8 percent and described it as “... very international, but hardly feminine” (Simon Kucher \& Partner, 2011). The following table provides an overview of the development from 2000 to 2011 with respect to the companies that were continuously represented in the DAX-list over this period of time.

Table 2: Share of foreign board members in DAX-listed companies from 2005 to 2011 compared to 2000.

\begin{tabular}{|c|c|c|c|c|c|c|c|c|}
\hline \multirow[b]{2}{*}{ DAX-listed company } & \multicolumn{8}{|c|}{ KP ${ }_{\text {Index }}$ (share of foreign board members of DAX-listed companies in \% ) } \\
\hline & 2000 & 2005 & 2006 & 2007 & 2008 & 2009 & 2010 & 2011 \\
\hline Adidas & $57.0 \%$ & $50.0 \%$ & $75.0 \%$ & $50.0 \%$ & $50.0 \%$ & $50.0 \%$ & $50.0 \%$ & $50.0 \%$ \\
\hline Allianz & $0.0 \%$ & $20.0 \%$ & $45.0 \%$ & $45.0 \%$ & $36.0 \%$ & $40.0 \%$ & $50.0 \%$ & $50.0 \%$ \\
\hline BASF & $13.0 \%$ & $12.5 \%$ & $11.0 \%$ & $11.0 \%$ & $0.0 \%$ & $0.0 \%$ & $0.0 \%$ & $0.0 \%$ \\
\hline Bayer & $13.0 \%$ & $0.0 \%$ & $0.0 \%$ & $0.0 \%$ & $0.0 \%$ & $0.0 \%$ & $20.0 \%$ & $25.0 \%$ \\
\hline BMW & $0.0 \%$ & $0.0 \%$ & $0.0 \%$ & $0.0 \%$ & $13.0 \%$ & $14.0 \%$ & $14.0 \%$ & $14.0 \%$ \\
\hline Commerzbank & $9.0 \%$ & $14.3 \%$ & $13.0 \%$ & $13.0 \%$ & $0.0 \%$ & $0.0 \%$ & $0.0 \%$ & $0.0 \%$ \\
\hline Daimler & $31.0 \%$ & $20.0 \%$ & $33.0 \%$ & $33.0 \%$ & $0.0 \%$ & $0.0 \%$ & $0.0 \%$ & $0.0 \%$ \\
\hline Deutsche Bank & $22.0 \%$ & $25.0 \%$ & $60.0 \%$ & $75.0 \%$ & $60.0 \%$ & $50.0 \%$ & $50.0 \%$ & $43.0 \%$ \\
\hline Deutsche Börse & $29.0 \%$ & $40.0 \%$ & $33.0 \%$ & $33.0 \%$ & $33.0 \%$ & $40.0 \%$ & $33.0 \%$ & $33.0 \%$ \\
\hline Deutsche Post & $0.0 \%$ & $12.5 \%$ & $22.0 \%$ & $25.0 \%$ & $38.0 \%$ & $33.0 \%$ & $43.0 \%$ & $57.0 \%$ \\
\hline Deutsche Telekom & $13.0 \%$ & $0.0 \%$ & $0.0 \%$ & $20.0 \%$ & $17.0 \%$ & $25.0 \%$ & $25.0 \%$ & $29.0 \%$ \\
\hline E.ON & $0.0 \%$ & $0.0 \%$ & $0.0 \%$ & $0.0 \%$ & $0.0 \%$ & $0.0 \%$ & $20.0 \%$ & $17.0 \%$ \\
\hline Fresenius Med. Care & $75.0 \%$ & $85.7 \%$ & $86.0 \%$ & $86.0 \%$ & $86.0 \%$ & $86.0 \%$ & $86.0 \%$ & $86.0 \%$ \\
\hline Henkel & $33.0 \%$ & $57.1 \%$ & $57.0 \%$ & $57.0 \%$ & $60.0 \%$ & $60.0 \%$ & $60.0 \%$ & $60.0 \%$ \\
\hline Linde & $14.0 \%$ & $25.0 \%$ & $25.0 \%$ & $60.0 \%$ & $50.0 \%$ & $50.0 \%$ & $50.0 \%$ & $60.0 \%$ \\
\hline Lufthansa & $0.0 \%$ & $33.3 \%$ & $33.0 \%$ & $33.0 \%$ & $33.0 \%$ & $25.0 \%$ & $25.0 \%$ & $0.0 \%$ \\
\hline MAN-Gruppe & $0.0 \%$ & $14.7 \%$ & $25.0 \%$ & $33.0 \%$ & $33.0 \%$ & $43.0 \%$ & $40,0 \%$ & $50.0 \%$ \\
\hline Metro Group & $20.0 \%$ & $0.0 \%$ & $25.0 \%$ & $25.0 \%$ & $40.0 \%$ & $40.0 \%$ & $40.0 \%$ & $50.0 \%$ \\
\hline MünchenerRück & $17.0 \%$ & $20.0 \%$ & $20.0 \%$ & $13.0 \%$ & $0.0 \%$ & $0.0 \%$ & $0.0 \%$ & $0.0 \%$ \\
\hline RWE & $0.0 \%$ & $50.0 \%$ & $40.0 \%$ & $20.0 \%$ & $0.0 \%$ & $0.0 \%$ & $0.0 \%$ & $0.0 \%$ \\
\hline SAP & $0.0 \%$ & $14.3 \%$ & $14.0 \%$ & $0.0 \%$ & $40.0 \%$ & $57.0 \%$ & $50.0 \%$ & $60.0 \%$ \\
\hline Siemens & $0.0 \%$ & $8.3 \%$ & $15.0 \%$ & $18.0 \%$ & $38.0 \%$ & $38.0 \%$ & $44.0 \%$ & $40.0 \%$ \\
\hline ThyssenKrupp & $0.0 \%$ & $0.0 \%$ & $10.0 \%$ & $0.0 \%$ & $0.0 \%$ & $0.0 \%$ & $0.0 \%$ & $0.0 \%$ \\
\hline Volkswagen & $40.0 \%$ & $33.3 \%$ & $33.0 \%$ & $40.0 \%$ & $40.0 \%$ & $40.0 \%$ & $43.0 \%$ & $38.0 \%$ \\
\hline Average share of foreign board members & $13.3 \%$ & $20.4 \%$ & $24.1 \%$ & $24.7 \%$ & $25.0 \%$ & $26.3 \%$ & $28.1 \%$ & $27.8 \%$ \\
\hline
\end{tabular}

Note. Own illustration on the basis of data by Simon Kucher \& Partners, 2005 - 2011; http://www.simon-kucher.com

Generally, the results show an increase in almost all companies. However, there are surprising results for companies such as, for example, ThyssenKrupp, Daimler, Commerzbank and BASF that seemingly have no internationality or even declining values even though these companies were active and successful in the international environment in recent years. The question arises if these management boards really show a low internationality rate or if, rather, there is room for improvement as far as the measuring methodology is concerned. For the detection of the internationality of individual board members, this means that they are regarded as international and that the index KP Index P takes the value " 1 " if the respective board member has a nationality other than the German one (Simon Kucher \& Partner, 2011). In case of German nationality the index takes the value " 0 ".

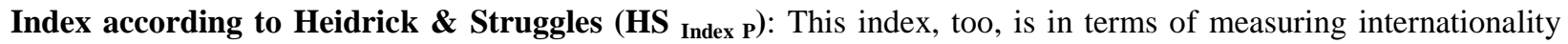
based on the assumption that internationality can be deduced from the share of foreign board members in a management board (Heidrick \& Struggles, 2011, p. 37). In the following, this index will be called HS ${ }_{\text {Index }}$. As the British consulting firm has waived its own nomenclature the formula below will be used: 


$$
\mathrm{HS}_{\text {Index }}=\frac{\text { number of foreign board members of a company }}{\text { total number of board members of a company }}
$$

However, the authors, too, express their doubts about the usefulness to determine internationality in the above mentioned form: “... However, internationalization is not easily achieved and it can be equally viable to have directors with international exposure rather than a non-national director in many cases" (Heidrick \& Struggles, 2011, p. 37). Therefore, the authors come to the following conclusion: “...Increasing diversity by simply adding people of different nationalities can miss the point" (Heidrick \& Struggles, 2011, p. 37). These statements illustrate that the authors consider it useful to include international work experience in addition to the nationality aspect. In the analysis below we will examine only one individual ("P") so that the index HS Index P takes the value " 0 " if the person is a native and " 1 " if the person is a foreigner.

Spencer Stuart Board Index (SSB Index P): The British consulting firm Spencer Stuart, too, does not formulate an explicit index but presumes implicitly. Therefore, the formula below will be called SSB Index (Spencer Stuart, 2010, p. 30):

$$
\mathrm{SSB}_{\text {Index }}=\frac{\text { number of foreign board members of a company }}{\text { total number of board members of a company }}
$$

The authors come to the result that the internationality of board members of DAX-listed companies has increased by 26 percent. At the same time, the authors mention the origin of foreign board members thus pointing out the importance of this aspect (Spencer Stuart, 2010, p. 30), which results in a detailed summary for each company (Spencer Stuart, 2010, pp. 60 et seqq.). A merging of both aspects into one index doesn't happen. In the analysis below we will examine only one individual ("P") so that the index SSB Index P takes the value "0" if the person is a native and " 1 " if the person is a foreigner.

Global Board Capabilities Index (GBC Index P) according to Egon Zehnder International: Unlike the indices mentioned above international experience is explicitly integrated into this index: “... The Global Board Capabilities Index is calculated by taking a simple average of these two data points for each company: the percentage of foreign nationals serving on a given board and the percentage of directors with international work experience" (Egon Zehnder International, 2008, p. 13). Hence the index can be described as follows:

$$
\mathrm{GBC}_{\text {Index }}=\frac{\% \text { of foreign directors }+\% \text { directors with intern.experience }}{2}
$$

When examining the S \& P 500 the American consulting firm came to the following results: “ $\ldots$ the simple average of percentage of foreign directors and directors with meaningful international work experience is 16.4 percent for all S \& P 500 companies" (Egon Zehnder International, 2008, p. 14). The percentage rate is probably determined on the basis of 0 percent for "no international experience or native" and 100 percent for "international experience or foreigner". A detailed explanation could not be found in the original paper by Egon Zehnder International (2008). The Global Board Capabilities Index Index P describes the facts with regard to one person, that means, 0 “ for a native without international experience and a maximum of „1“ for a foreigner with international experience.

Logarithmic Board Internationalization Index $\left(\mathbf{I N T}_{\log \mathbf{P}}\right)$ according to Schmid and Daniel: This index can be seen as a further development of previous indices since it includes at the same time various considerations like for example nationality, international work experience or educational aspects (Schmid \& Daniel, 2006, pp. 15 et seqq.). Like the indices mentioned above, it is designed for a comprehensive survey of a company, however, it can as well be used for an individual person $\mathrm{P}$ if the number of board members is appointed $\mathrm{n}=1$ (Schmid \& Daniel, 2006, pp. 15 et seqq.):

$$
I N T_{\log }=\frac{1}{n} * \sum_{i=1}^{n}\left\{\frac{1}{4}\left[F_{i}+\left(1-\frac{1}{\left(E_{i f}+1\right)}\right)+\left(1-\frac{1}{\left(W_{i f}+1\right)}\right)+\left(1-\frac{1}{\left(A_{i f}+1\right)}\right)\right]\right\}
$$


Note. n: $\quad$ Total number of the executive board or supervisory board members

$\mathrm{F}_{\mathrm{i}}$ : $\quad$ Nationality of person $\mathrm{i} ; \mathrm{F}=0$ for Germany; $\mathrm{F}=1$ for foreign countries

$\mathrm{E}_{\mathrm{IF}}$ : $\quad$ Number of training years of person $\mathrm{i}$ in country spent abroad $\mathrm{f}$

$\mathrm{W}_{\text {if }}$ : $\quad$ Number of working years of person $\mathrm{i}$ in country $\mathrm{f}$ spent abroad

$\mathrm{A}_{\mathrm{if}}$ : $\quad$ Number of mandates at enterprises abroad of person $\mathrm{i}$ in country $\mathrm{f}$

If only one individual person $(\mathrm{P})$ is examined $(\mathrm{n}=1)$, the letter „P“" is attached to the index $\left(\mathrm{INT}{ }_{\log \mathrm{P}}\right)$. The value of the index varies between 0 and 1; 1 being the maximum value in terms of the internationality of a board member. Concerning possible differences with regard to the contribution of individual components to the overall result (for example, nationality versus international work experience) the authors give their opinion as follows "... in this study no different weights are used for the individual dimensions as we assume that the four index components represent different areas of experience and of leaning and that they are equally important" (Schmid \& Daniel, 2006, pp. 15 et seqq.). This may require further research with respect to the weighting on the one hand and to the presentation in the form of sub-indices on the other hand (Sommer, 2009). With regard to the internationality of board members ${ }^{1}$ the index delivered the following results, which for comparison purposes were combined with the results of Simon Kucher \& Partners (Schmid \& Daniel, 2006, p. 47; Simon Kucher \& Partners, 2005 - 2011) as follows:

Table 3: Comparison of internationality indices KP Index $_{\text {with INT }}$ log of selected board members of DAX-listed companies (based on data of 2005)

\begin{tabular}{llll}
\hline & KP $_{\text {Index }}$ & INT $_{\text {log }}$ & $\Delta$ Delta \\
\hline Selected DAX-Members & $\mathbf{2 0 0 5}$ & $\mathbf{2 0 0 5}$ & $\mathbf{2 0 0 5}$ \\
Adidas & $50.0 \%$ & $33.39 \%$ & $16.61 \%$ \\
Allianz & $20.0 \%$ & $37.14 \%$ & $-17.14 \%$ \\
BASF & $12.5 \%$ & $35.36 \%$ & $-22.86 \%$ \\
Bayer & $0.0 \%$ & $18.13 \%$ & $-18.13 \%$ \\
BMW & $0.0 \%$ & $25.97 \%$ & $-25.97 \%$ \\
Commerzbank & $14.3 \%$ & $38.50 \%$ & $-24.20 \%$ \\
Daimler & $20.0 \%$ & $39.64 \%$ & $-19.64 \%$ \\
Deutsche Bank & $25.0 \%$ & $38.69 \%$ & $-13.69 \%$ \\
Deutsche Börse & $40.0 \%$ & $86.53 \%$ & $-46.53 \%$ \\
Deutsche Post & $12.5 \%$ & $29.37 \%$ & $-16.87 \%$ \\
Deutsche Telekom & $0.0 \%$ & $13.43 \%$ & $-13.43 \%$ \\
E.ON & $0.0 \%$ & $23.44 \%$ & $-23.44 \%$ \\
Fresenius Medical Care & $85.7 \%$ & $71.58 \%$ & $14.12 \%$ \\
Henkel & $57.1 \%$ & $62.58 \%$ & $-5.48 \%$ \\
Linde & $25.0 \%$ & $26.71 \%$ & $-1.71 \%$ \\
Lufthansa & $33.3 \%$ & $32.41 \%$ & $0.89 \%$ \\
MAN-Gruppe & $14.7 \%$ & $24.00 \%$ & $-9.30 \%$ \\
Metro Group & $0.0 \%$ & $13.54 \%$ & $-13.54 \%$ \\
MünchenerRück & $20.0 \%$ & $28.87 \%$ & $-8.87 \%$ \\
RWE & $50.0 \%$ & $36.43 \%$ & $13.57 \%$ \\
SAP & $14.3 \%$ & $24.33 \%$ & $-10.03 \%$ \\
Siemens & $8.3 \%$ & $-38.78 \%$ \\
ThyssenKrupp & $0.0 \%$ & $47.08 \%$ & $-36.57 \%$ \\
Volkswagen & $33.3 \%$ & $36.57 \%$ & $9.52 \%$ \\
\hline Note. Own & $23.78 \%$ & \\
\end{tabular}

Note. Own illustration based on data of Simon Kucher \& Partners (2005 - 2011) and Schmid and Daniel (2006)

The comparison shows that the divergences between the indices are significant. For instance, the KP Index allocates an index value of 0 percent to ThyssenKrupp in 2005 whereas INT ${ }_{\log }$ displays a value of 36.7 percent. In all surveyed companies the results diverge to such an extent that there is doubtlessly need for further research with regard to the verification of the findings.

\footnotetext{
${ }^{1}$ Schmid and Daniel examined the internationality of management board members as well as of supervisory board members. The observations below refer exclusively to management board members to ensure comparability with the research of Simon Kucher \& Partners.
} 
International Work Experience Index (InEx $x_{W E}$ P) according to Sommer (2012): This index represents a further development of the above indices with a focus on "work experience (WE)". In the absence of primary data (for example from interviews) this index, too, is based on secondary data, particularly from CVs. The objective is to capture international experience through a meaningful and at the same time measurable variable which is available in the form of secondary data. Here, the number of years spent abroad would be useful since these years have inevitably led to a confrontation with the international environment and can therefore be regarded as international experience (IE). These years of international experience can be acquired in a professional (IE WE) or nonprofessional (IE $\mathrm{NWE}_{\text {) }}$ environment, as confirmed by the studies of Roth (1995), Reuber and Fischer (1997) or Herrmann and Datta (2002). In addition to a stay abroad, it is also possible to gain international experience (IE) from activities associated with the international environment even without the person in question spending an extended period of time abroad. However, since usually on the one hand information on international experience in the form of secondary data is not available and on the other hand the comparability of such experience is associated with considerable difficulties of valuation (for example, how do you evaluate a one-week stay in China compared to two months of project coordination with Chinese partners via telephone / internet / video conferencing) we will abandon the option of using it at all. So, if we only consider the years spent abroad in a professional context (Y), they can be subdivided into different categories. Sommer (2012) has identified four factors for weighting the years spent abroad as, in his opinion, not all years spent abroad do automatically have the same importance in terms of international experience IE (Sommer, 2012, pp. 8 et seqq.):

a) Learning Effect $\left(L E_{\text {Norm }}\right)$ : this means that in an early phase of learning the learning effect - depending on the source of literature - is classified as higher than in later stages of learning. Following this logic Schmid and Daniel (2006) argue as follows: “... A logarithmic function better corresponds to theories of intercultural learning than does a linear function" (Schmid \& Daniel, 2006, p. 16). Schmid and Daniel give further reason by pointing out that "... short stays abroad can have a large impact on intercultural sensitivity and awareness while after some years the learning curve flattens and additional time spent abroad only leads to limited additional effects" (Schmid \& Daniel, 2006, p. 16). Authors like Willcocks (2011) prefer an s-shaped curve (Willcocks, 2011, p. 9). For simplicity reasons, a linear course was assumed for the present study which produces an LE value of 1. Further studies seem necessary.

b) Cultural Difference ( $C D_{\text {Norm }}$ ) helps considering the fact that there are different cultural distances between different countries. Hofstede (1980) as well as House et al. (2004) have provided a substantial scientific basis that allows for differentiation. For lack of other concepts, their works, although scientifically controversial, will be used as a basis for the paper at hand. The formation of the index is based on the proposal of Kogut and Singh (Kogut \& Singh, 1988, p. 422):

$$
C D_{I E}=\sum_{i=1}^{4} \frac{\left(I_{i j}-I_{i h}\right)^{2}}{4 V_{i}}
$$

Note. $\mathrm{CD}_{\mathrm{IE}-\mathrm{Norm}}=$ Cultural Difference for International Experience IE; $1_{\mathrm{ij}}=$ Index of the cultural dimension $\mathrm{i}$ abroad $\mathrm{j} ; \mathrm{l}_{\mathrm{ih}}=$ Index of the cultural dimension in the home country $\mathrm{h} ; \mathrm{V}_{\mathrm{i}}=$ variance of the index of dimension $\mathrm{i}$

The data set of the index $1_{\mathrm{ij}}$ or $\mathrm{l}_{\mathrm{ih}}$ and $\mathrm{V}_{\mathrm{i}}$ is based on the values of Hofstede (2012) which can be taken from his website (Hofstede, 2012). To counter the objection made by Hofstede himself concerning the simple aggregation or multiplication of Cultural Difference (CD) (Hofstede, 2001, p. 17) on the one hand, and to prevent a disproportionate devaluation of the cultural experience gained in countries with cultures similar to the German one on the other hand, a standardization via logarithmic function is carried out (Schmid \& Daniel, 2006, p. 14) which leads to values for CD Norm between 0 and 1.

c) Salary Differentials $\left(S D_{\text {Norm }}\right.$ ): The years spent abroad $(\mathrm{Y})$ must also been seen under the aspect of management relevance, i.e., international experience gained in top management levels is usually more important for board activities than international experience gained in lower levels (Sommer, 2012). Accordingly, the different activities must be assigned a certain value. A possible basis of valuation - albeit 
not free of distortion - is remuneration because this, at least in principle, reflects the value from the employer's point of view. Salary differentials (SD) can thus serve as a clue for values ${ }^{2}$. If, for example, we act on the assumption of a baseline salary of a manager in training of $S_{B}=10,000 €$ and compare it to the income of a board member of 1.4 million $€$ we obtain a SD $\mathrm{IE}$ value of 140 ! The following formula illustrates the approach (Sommer, 2012, pp. 9 et seqq.):

$$
S D_{I E}=\frac{S_{i}}{S_{B}}
$$

Note. $\mathrm{SD}_{\mathrm{IE}}=$ Salary Differentials; $\mathrm{S}_{\mathrm{i}}=$ Salary in the relevant period $\mathrm{E} ; \mathrm{S}_{\mathrm{B}}=$ Baseline Salary

Taking into consideration that salary differentials have only a limited informative value and that, without standardization, lower incomes would be underestimated as value measure for international management knowledge, this value, too, is standardized by using a logarithmic function (Schmid \& Daniel, 2006, p. 14). The result is an $\mathrm{SD}_{\text {Norm }}$ value between 0 and 1 as maximum value.

d) Forgetting Effect $\left(F E_{\text {Norm }}\right.$ ): As fourth factor we will consider the aspect of forgetting knowledge over time. For doing so, we will resort to the findings of Wixted and Ebbesen (1991) who defined the following function which delivers standardized values between 0 and 1 (Wixted \& Ebbesen, 1991, p. 413):

$$
F E_{I E-n o r m}=P C_{I E-n o r m}=\frac{\left(a \times t^{-b}\right)+1}{\left(a \times t^{-b}\right)+2}
$$

Note. $\mathrm{FE}_{\mathrm{IE}-\mathrm{norm}}=\mathrm{PC}_{\mathrm{IE} \text {-norm }}=$ Proportion Correct for International Experience IE; $\mathrm{a}=$ Factor; $\mathrm{b}=$ Factor; $\mathrm{t}=$ moment of consideration $^{3}$

Based on the four factors mentioned above we can now individually evaluate international work experience (IE wE) and formulate the personalized international work experience index ( $\mathbf{I n E x} \mathbf{w E}_{\mathbf{p}}$ ). Every international experience IE wE gained since the start of training (for example, academic education / vocational training) will be taken into consideration. Thus, e.g. five years of international work experience gained 20 years ago as a young professional in Austria have another significance than five years of experience as a board member gained two years ago in China (Sommer, 2012). The resulting index $\left(\mathrm{InEx}_{\mathrm{WE}}\right)$ is based on the multiplication of the four factors with the respective number of years of international employment (Sommer, 2012, pp. 10 et seqq.):

$$
I n E x_{W E P}=\sum_{I E=1}^{n} \quad\left[Y_{I E} \times L E_{I E-n o r m} \times\left(1-\frac{1}{C D_{I E}+1}\right) \times\left(1-\frac{1}{S D_{I E}+1}\right) \times F E_{I E-n o r m}\right]
$$

Considering the standardization of $\mathrm{CD}_{\mathrm{IE}}$ and $\mathrm{SD}_{\mathrm{IE}}$, that is, the introduction of $\mathrm{CD}_{\mathrm{IE}}$ Norm and $\mathrm{SD}_{\mathrm{IE}}$ Norm we receive the following formula (Sommer, 2012, pp. 10 et seqq.):

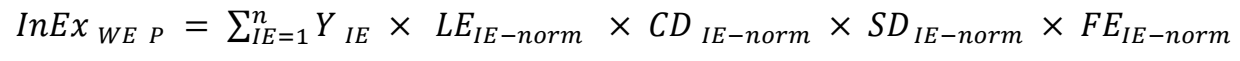

Note. $\operatorname{InEx}_{\mathrm{WE}}=$ International Work Experience Index per person $(\mathrm{P}) ; \mathrm{Y}=$ International Work Experience in years; $\mathrm{IE}=$ International Experience, where $\mathrm{n}$ is the complete set of these experiences; $\mathrm{CD}=$ Cultural Differences; Distances; SD = Salary Differentials; FE = Forgetting Effect; LE = Learning Effect

\footnotetext{
${ }^{2}$ The following assumptions were made (Sommer, 2012, pp. 9 et seqq.): the estimated maximum income of board members of DAX-listed companies is at 1.4 million on average. Divided by 10,000 , we receive a standardized value of 140 . Top level managers are at a standardized value of 70; medium level managers at 14; low level managers at 10, young professionals at 4; undergraduate students at 1 ; pupils / trainees at 0.5 . The latter group, too, acquires management relevant skills (for example, language skills) which represent a necessary basis for a future career, so that this group was evaluated as well. The evaluation is based on the assumption that the payment for unskilled jobs is at approximately 5,000 € a year which corresponds to a value of 0.5 .

${ }^{3}$ The values of the factors are defined as follows: $a=30 ; b=1$; these assumptions are based on the works of Bahrick (1984) and Bahrick et al. (1993), respectively.
} 
The index above is not standardized. The minimum value is 0 . If it is desired to capture international nonwork experience (IE $\mathrm{NWE}$ ) which results from a person's school days, nationality ${ }^{4}$ (= life abroad) or immigration background the aspects below have to be taken into consideration. Provided that there are no reliable secondary data, we will consider in the framework of the paper at hand only the consistently practiced nationality with an amount of 20 years (Y). As a rule, secondary data does not allow for reliable conclusions in terms of school days and immigration background. A person's international non-work experience is integrated in the above index. However, unlike the approach of Schmid and Daniel (2006) not via a „Yes/No decision“ but, depending on the nature of the years spent abroad, weighted with the factors $\mathrm{CD}_{\text {Norm }}, \mathrm{SD}_{\text {Norm }}, \mathrm{FE}_{\text {Norm }}$ and $\mathrm{LE}_{\text {Norm. }}$. All factors can be adopted for NWE, as well. However, $\mathrm{SD}_{\text {Norm }}$ has to be examined with regard to the question whether or not we can determine a value that reflects the job-relevant experience resulting from school education (for example language skills, eloquence and presentation skills). To sum up, the following index can be formulated:

$$
I n E x_{N W E+W E P}=\sum_{I E=1}^{n} Y_{I E} \times L E_{I E-n o r m} \times C D_{I E-n o r m} \times S D_{I E-n o r m} \times F E_{I E-n o r m}
$$

Note. InEx ${ }_{\mathrm{NEW}+\mathrm{WE}} \mathrm{P}=$ International Experience Index per Person $(\mathrm{P}) ; \mathrm{Y}=$ International Experience in years; IE $=$ International Experience, where $\mathrm{n}$ is the complete set of these experiences; $\mathrm{CD}=$ Cultural Differences; Distances; $\mathrm{SD}=$ Salary Differentials; FE $=$ Forgetting Effect $; \mathrm{LE}=$ Learning Effect

The five indices presented above shall now be compared with regard to the different statements in terms of the internationality of an individual person P. For this purpose, the following hypotheses are formulated:

Hypothesis 1: Measuring the internationality of board members by their nationality only leads to significant distortions compared to measuring methods that integrate the aspects of time (LE effect or FE effect), cultural differences (CD) and management competence (SD).

The distortions documented in table 3 reveal significant differences between KP ${ }_{\text {Index }}$ and INT $\log$. For ThyssenKrupp, for example, the KP Index shows a value of 0 percent whereas INT log reaches a value of 36.57 percent. The latter is based on a complex structure that, in addition to nationality, integrates further professional or pre-vocational experience.

Hypothesis 2: A non-weighted additive counting of different forms / dimensions of international experience (IE) like in INT $\log _{\mathrm{P}}$ leads to significant distortions compared to a weighted counting.

By means of the second hypothesis we want to check, for the more complex indices in particular, whether there are deviations which according to Hofstede (1980) and House et al. (2004) could amongst other things be due to the fact that for example the INT ${ }_{\log }$ index doesn't include cultural differences or a differentiated weighting of its index components: “. ...in this study no different weights are used for the individual dimensions as we assume that the four index components represent different areas of experience and of learning and that they are equally important" (Schmid \& Daniel, 2006, p. 15). The assumption/question whether or not different forms/dimensions are equally weighted and summable in the sense of INT $\log$ P shall be verified by direct comparison with the weighted InEx NWE+WE P.

Hypothesis 3: The information value of a single index can be increased significantly by consulting supplementary indices relating to international experience (IE).

The last hypothesis deals with the question if a single index can lead to significant misinterpretations, i.e., if supplementary outsourced indices represent a useful alternative. As a rule, it can be assumed that the reduction of data to one index is generally associated with the loss of information. The aim of the above hypothesis is to examine if this loss is significant and if relevant distortions in interpretation could possibly result out of it. In order to disclose possible misinterpretations we will introduce the Diversity Index (DIV NWE+WE P) in addition to the respective index

\footnotetext{
${ }^{4}$ This means a nationality other than German, provided that the person has spent the time in question in his/her native country. A nationality other than German is not relevant if the time in question was not spent in the native country. In this case it would be assigned to the immigration category. 
which shall document the cultural diversity of the years spent abroad. For example, 10 years abroad could have been spent in one country or in five different countries which can lead to a different weighting of these 10 years.

The following formula for the Diversity Index can be traced back to an approach of Simpson (Simpson, 1949, pp. 688 et seqq. / Harrison \& Klein, 2007, pp. 1199 et seqq.):

$$
D I V_{N W E+W E P}=1-\frac{\sum y(y-1)}{Y(Y-1)}
$$

Note. DIV ${ }_{\text {NEW+WE }}=$ Diversity Index for International Work Experience $\&$ International Non-Work Experience; $y=$ International Work \& Non-Work Experience in years relating to different phases of life / activities, standardized to 100 percent, $\mathrm{Y}=$ total number of years, which standardized correspond to 100 percent

The index reaches its maximum value at DIV $\mathrm{NWE}_{\mathrm{WE} P}=1$ which means that in this case a board member would have gained his or her international experience relatively evenly distributed in a variety of countries, whereas an index value of 0 stands for no international experience at all or experience gained in one country only.

\section{METHOD}

As relevant data sets were available in sufficient quantity, the descriptive form of a survey was chosen as research design. For the implementation of the project the 30 DAX-listed companies of 2010 were examined. For this purpose, the CVs of the board members in question were analyzed. The information was taken from websites, data bases and publications according to annex 1 . The resulting data base was the outcome of an unpublished student project of the Department of Business Administration and Engineering of the Albstadt-Sigmaringen University (ASU) from 2011 (Albstadt-Sigmaringen University, 2011). The data base was adopted, modified and supplemented by the author and, in the framework of the paper at hand, adapted to the indices to be tested. After revision of the data base, there remained 213 data sets that seemed to be suitable for testing via indices. The rest of the data sets had to be rejected due to inconsistency, defectiveness or missing data. The following data were collected (AlbstadtSigmaringen University, 2011): (1) company, (2) nationality, (3) native country, (4) age, (5) immigration background, (6) school education / academic studies / vocational training with indication of country and specification of time and degree, (7) work experience with specification of position, employer, time and location. The results of the research showed that the CVs, in part, contained inconsistencies so that in some cases estimations had to be made: (1) academic degrees: for a Bachelor's degree 3 years, for a Master's degree 2 years, for a Diplom (German academic degree) 5 years, for a $\mathrm{PhD} 3$ years and for a semester abroad 1 year; (2) for the duration of childhood until the start of academic studies / vocational training 20 years were determined, provided that no other data were available; (3) information concerning positions outside Germany could be detected only fragmentarily, thus it was omitted. Details for random examination can be taken from annex 2.

\section{RESULTS}

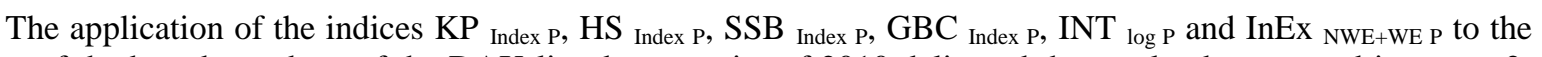
data sets of the board members of the DAX-listed companies of 2010 delivered the results documented in annex 2. The case study below illustrates the calculations made in annex 2 :

Board member no. 93 (Albstadt-Sigmaringen University, 2011), aged 54, was born and raised (1957 - 1977) in the United States. After 5 years of studies in the US (1982), first professional activity as a beginner (1982-1984); subsequently no. 93 was employed in the US as a low level manager (1984 - 2000). Then, no. 93 was employed as medium level manager in France (2000 - 2003). Since 2003, no. 93 has been employed as board member in various companies in Germany. 
Based on these data the following values can be calculated ${ }^{5}$ :

a) $\quad$ KP Index P / $_{\text {HS }}$ Index P / SSB Index P: all three indices show a value of "1 " as the board member was born abroad which means that the highest internationality level of the above indices is reached.

b) $\quad \mathbf{G B C}_{\text {Index }} \mathbf{p}$ : this index captures international experience in addition to nationality, however, only a yes/no query is provided for. Board member no. 93 meets both criteria so that the maximum value of " 1 " is achieved again.

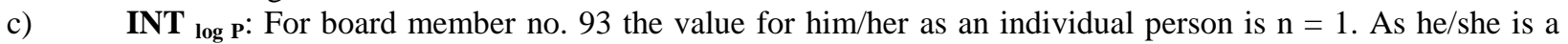
foreigner $\mathrm{F}$ has the value " 1 ". E has the value " 5 " due to the five years of studies spent abroad, and due to three stays abroad $\mathrm{W}$ has the value $\mathrm{W}=2+16+3=21$. For positions outside Germany no assured values could be detected so that the value $\mathrm{A}=0$ was determined. This leads to the following value:

$$
\begin{aligned}
& \mathrm{INT}_{\log \mathrm{P}}=1 / 1 *\{1 / 4 *[1+(1-1 /(5+1))+(1-1 /(21+1))+(1-1 /(0+1))]\} \\
& \mathrm{INT}_{\log \mathrm{P}}=\mathbf{0 , 7 0}
\end{aligned}
$$

This value can be regarded as relatively high, even though the maximum value of "1" is not achieved.

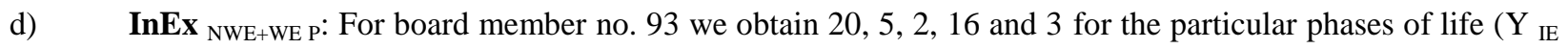
$=\mathrm{Y}_{\mathrm{IE} \mathrm{NWE}}+\mathrm{Y}_{\mathrm{IE} \mathrm{WE}}=46$ years). For LE $\mathrm{IE}_{\mathrm{IE}-\mathrm{Norm}}$ we are assuming that its value is generally determined as „1“. According to the Kogut and Singh index (Kogut \& Singh, 1988, p. 422) and the values for cultural dimensions provided by Hofstede (2012), the $\mathrm{CD}_{\mathrm{IE}}$ for the USA is 0.41 and for France it is 1.19 . For $\mathrm{SD}_{\mathrm{IE}}$, the non-work experience phase of the first 20 years of life yields a value of 0.5 . The five years of pre-work experience yield a value of 1 , the two years as a beginner yield a value of 4 , the sixteen years as a low level manager yield a value of 10 and the three years a medium level manager yield a value of 14 . The forgetting effect FE ${ }_{\text {IE Norm }}$ results from the formula of Wixted and Ebbesen (1991). Here, the values $a=30$ and $b=1$ are determined (Wixted \& Ebbesen, 1991, p. 413). For example, the stay in France ended in 2003 which counted from 2011 - corresponds to eight years $(t=2011-2003=8)$. This yields the following FE IE Norm $=$ $\mathrm{PC}_{\text {IE Norm value: }}$

$$
\mathrm{FE}_{\mathrm{IE} \mathrm{Norm}}=\left(30 * 8^{-1}\right)+1 /\left(30 * 8^{-1}\right)+2=0.826
$$

For the other years of international experience (IE) we have values of 0.65 (20 years), 0.670 (5 years), 0.679 (two years) and 0.788 (16 years). Hence, we get the total value below for the index of international experience IE $=4$ phases of life with international experience:

$$
\begin{aligned}
\text { InEx }_{\mathrm{NWE}+\mathrm{WEP} P}= & \{[20 * 1 *(1-1 /(0.41+1)) *(1-1 /(0.5+1)) * 0.65] \\
& +[5 * 1 *(1-1 /(0.41+1)) *(1-1 /(1+1)) * 0.67] \\
& +[2 * 1 *(1-1 /(0.41+1)) *(1-1 /(4+1)) * 0.679] \\
& +[16 * 1 *(1-1 /(0.41+1)) *(1-1 /(10+1)) * 0.788] \\
& +[3 * 1 *(1-1 /(1.19+1)) *(1-1 /(14+1)) * 0.826]\} \\
= & \mathbf{6 . 6 6}
\end{aligned}
$$

\footnotetext{
${ }^{5}$ See Chapter: Introduction
} 
The figure below illustrates the influence of weighting on international experience:

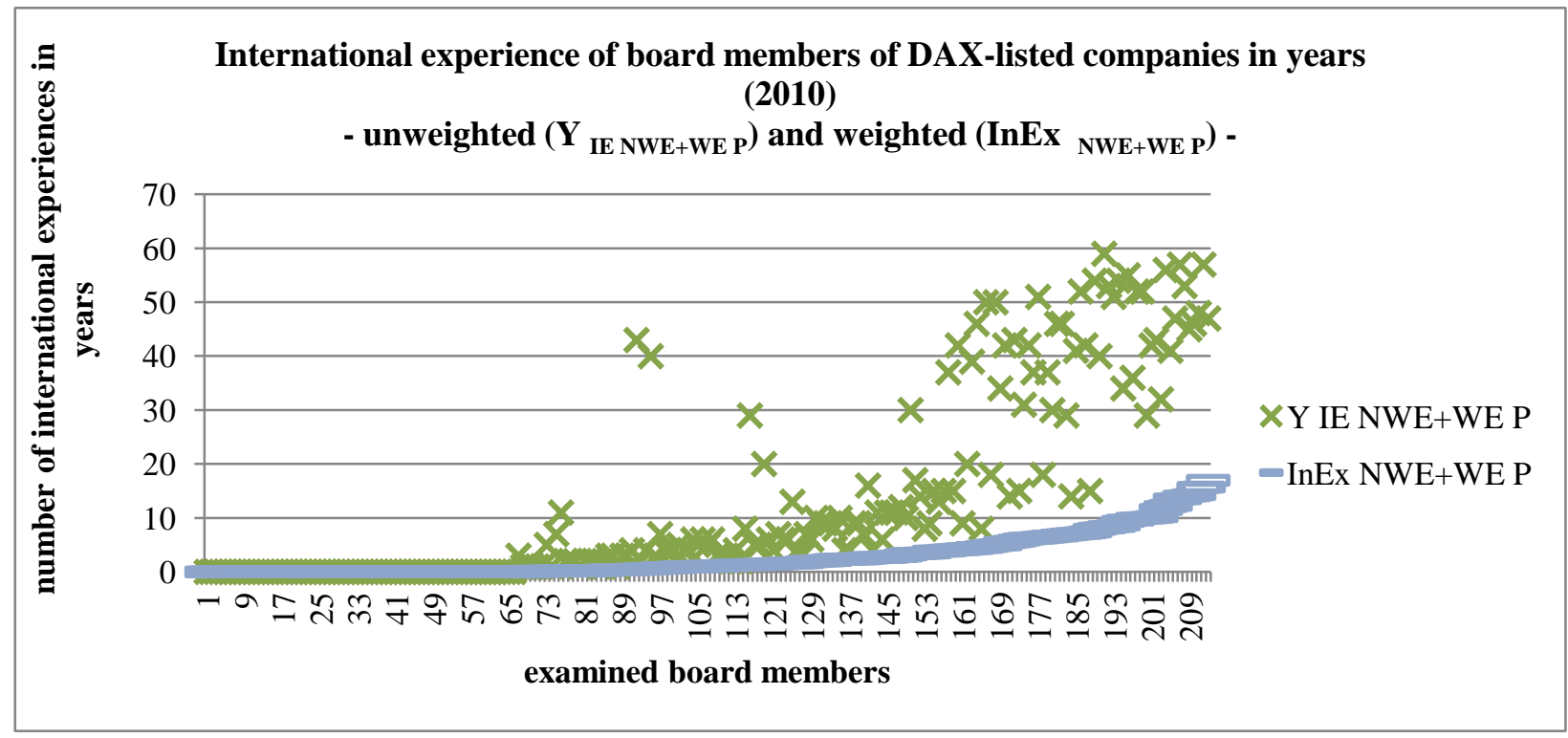

Figure 1: International experience of board members of DAX-listed companies in years (2010) in unweighted $\left(Y_{\text {IE NWE+WE } P}\right)$ and in weighted (InEx ${ }_{N W E+W E ~}$ ) presentation

Note. Own illustration showing the values of 213 board members of DAX-listed companies based on a supplemented / modified data base of the Albstadt-Sigmaringen University (Albstadt-Sigmaringen University, 2011)

e) DIV NWE+WE P: Here, we obtain for board member no. 93 the value y usA $=43(20+5+2+16=43)$ for the years spent in the USA and $Y_{\text {France }}=3$ for the years spent in France. The total number of years $Y_{\text {IE NEW+WE } P}$ is 46. Consequently, the index can be determined as follows:

$$
\begin{aligned}
\text { DIV }_{\text {NWE+WE }} \mathrm{P} & =1-[43 *(42-1)+3 *(3-1)] /[46 *(46-1)] \\
& =\mathbf{0 . 1 2}
\end{aligned}
$$

Comparing the indices INT $\log$ P, InEx ${ }_{\text {NWE+WE P }}$ and $\mathrm{KP}_{\text {Index }}$ (= representative for the simple indices), the figure below illustrates on a descriptive examination level the occurring deviations of the standardized indices $\mathrm{InEx}_{\text {Norm }}, \mathrm{INT}_{\text {Norm }}$ and KP ${ }_{\text {Norm }}$ : 


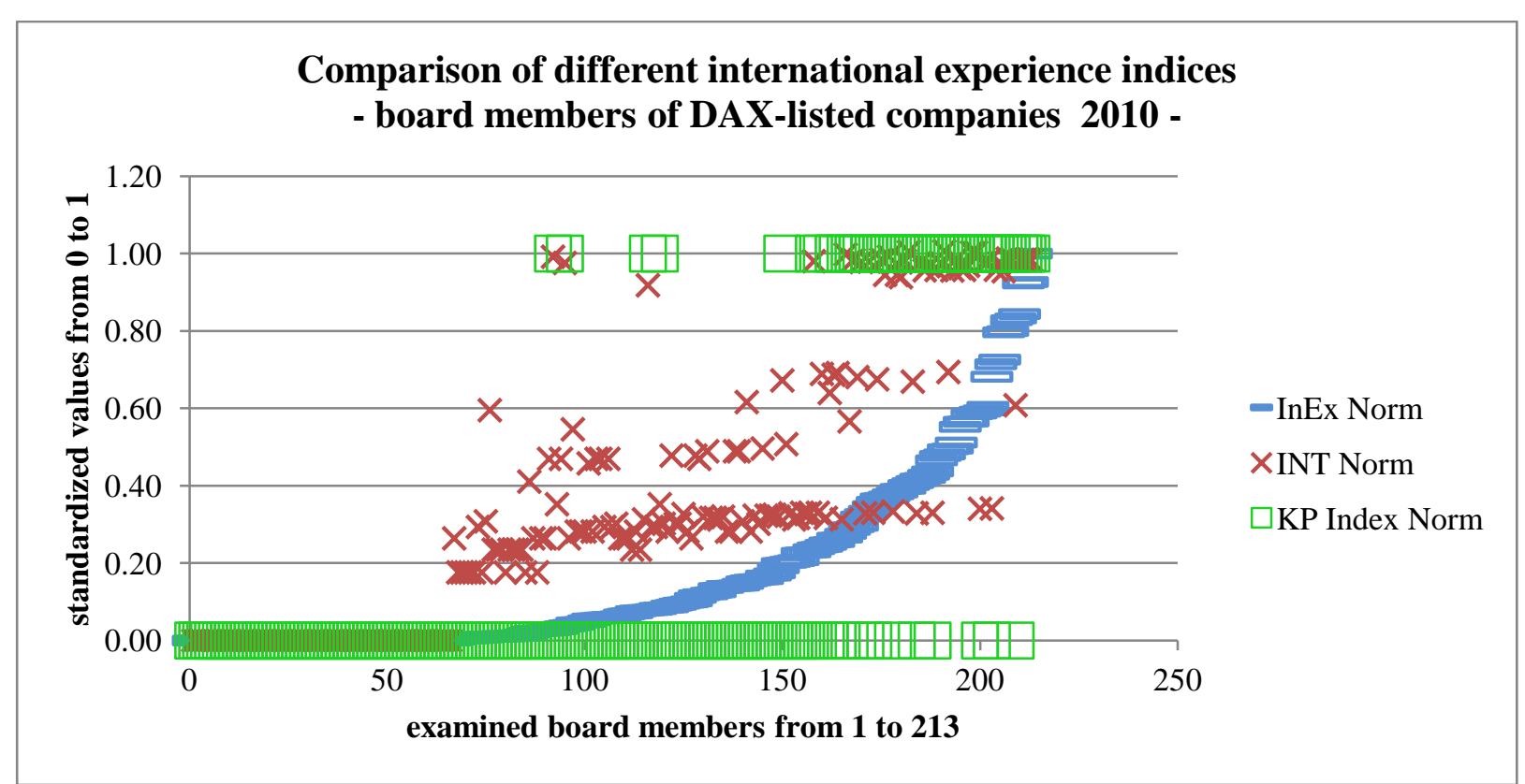

Figure 2: Comparison of different internationality indices related to board members of DAX-listed companies (2010) Note. Own illustration showing the values of 213 board members of DAX-listed companies based on a supplemented / modified data base of the Albstadt-Sigmaringen University (Albstadt-Sigmaringen University, 2011)

The data, sorted via InEx ${ }_{\text {Norm }}$ by ascending order, shows that the 213 board members can be divided into three groups. The first 66 board members have no international experience at all which leads to a value of " 0 " for all three indices. The next 99 board members do have international work experience (WE), however, they are natives. Here, the KP ${ }_{\text {Norm }}$ index always reaches a value of " 0 ", whereas the INT Norm value ranges between " 0.18 " and " 0.61 " and the InEx Norm value between " 0 " and " 0.83 ". The third group includes 48 board members who were born and raised abroad. Here, the KP Norm index always reaches the value "1" that stands for maximum internationality whereas the INT Norm index shows values between " 0.35 " and " 1 " and the InEx Norm index shows values between " 0.03 " and " 1 ". Thus, it becomes apparent that there are significant deviations for the latter two groups. The considerable differences shall be explained using the selected examples below (Albstadt-Sigmaringen University, 2011; see also annex 1):

Board member no. 159 (Albstadt-Sigmaringen University, 2011) is a sixty-year-old native who spent 3 years in South Africa (29 years ago during his studies) and four years in Italy as a medium level manager (13 years ago). The KP Norm value is " 0 ", whereas the INT Norm value is " 0.55 " and the InEx Norm is " 0.04 ". According to the INT Norm, board member no. 159 is an internationally experienced personality. However, this is contradictory to reality as the international experience was collected a relatively long time ago in countries culturally resembling Germany and only the stay in Italy was of high management relevance. Thus, the InEx Norm value of "0.04" turns out rather weak.

Board member no. 92 (Albstadt-Sigmaringen University, 2011), aged 56, is a native with 32 years of international experience consisting of 13 years in Great Britain as a beginner and low level manager (26 years ago) and 19 years in the Arab World as a low level and medium level manager (7 years ago). Here, too, the KP Norm value is " 0 ", the INT Norm value is " 0.34 " and the InEx Norm is " 0.68 ". Compared to board member no. 159 , board member no. 92 worked for a longer period of time in culturally more dissimilar countries in more management-relevant positions and has still been doing so lately. Thus, the InEx Norm shows a significantly higher value for no. 92 which can be regarded as plausible.

Board member no. 194 (Albstadt-Sigmaringen University, 2011) is a 57-year-old foreigner (Swiss nationality) with 19 years of international work experience consisting of 10 years in Switzerland (18 years ago), 4 years in Austria (8 years ago) and 5 years in the Netherlands ( 3 years ago). In other words, most of the international experience was collected in Switzerland and Austria which, according to Hofstede (2012), can be assessed as culturally "close". The 
positions held by no. 194 were in the low level and medium level management. For this person the index KP Norm shows a maximum value of " 1 ", the INT Norm a value of " 0.69 " and the InEx Norm a value of " 0.25 ". The discrepancy between the InEx Norm and the two other indices is due to the fact that this index takes the cultural proximity of Switzerland, Austria and Germany into consideration.

Board member no. 208 (Albstadt-Sigmaringen University, 2011): In this case, the board member was born and raised in Austria. However, this person has collected no further international experience and was employed in Germany. The indices deliver the following values: $\mathrm{KP}_{\text {Norm }}$ shows a maximum value of "1", INT ${ }_{\text {Norm }}$ shows a value of " 0.35 " and InEx Norm assesses this experience with " 0.08 ". The latter value seems to be plausible considering the low management relevance, the cultural proximity between Germany and Austria and the chronology.

Board member no. 112 (Albstadt-Sigmaringen University, 2011), aged 64, is a native with 45 years of international experience consisting of 10 years in the Netherlands as a student and as a top level manager, 33 years in Great Britain as a low level and a medium level manager and two years in the USA as a medium level manager. The latest international experience was collected in the recent past. The indices deliver the following values: KP ${ }_{\text {Norm }}$ shows a value of "0" which indicates no international background, INT Norm shows a value of " 0.61 " which is under the value of board member no. 194 and InEx Norm shows a value of " 0.83 ". The latter value can be explained by the fact that compared to board member no. 194 the candidate no. 112 stayed abroad for a longer period of time in culturally more dissimilar countries on the one hand and held positions on a higher management level on the other hand.

Board member no. 191 (Albstadt-Sigmaringen University, 2011): This person, too, features a broad international background. The 55-year-old board member with British origin possesses 31 years of international work experience in different management levels that were collected up to the recent past. The KP Norm index reaches a value of "1"and the INT Norm a value of " 0.96 ". In contrast to this, the InEx Norm shows a value of "only" " 0.50 " which is, as well, explainable. Great Britain belongs to the European culture area and is, according to Hofstede (2012), "culturally close" to Germany.

However, no index includes the fact that board member no. 191 collected international experience in one country only. For this purpose, we additionally have to apply the diversity index DIV NWE+WE P whose value of "0" illustrates the situation. All in all, board member no. 191 shows a high degree of "specialized" international experience. However, a more "universal" international experience is missing.

Board member no. 113 (Albstadt-Sigmaringen University, 2011): This person, too, features a broad international background. Born and raised in Norway, this board member collected 27 years of work experience in different management levels in his/her home country, similar to board member no. 191. The index values are KP ${ }_{\text {Norm }}=$ „,“, $\mathrm{INT}_{\text {Norm }}=$ " 0.98 " and InEx ${ }_{\text {Norm }}=$ "1". Due to the relatively large cultural distance between Germany and Norway, the InEx Norm would show a maximum value in this case. However, this would only be justified, if "special experience in Norway" were sought after.

The correct classification from the angle of ,universal international experience“ is again delivered by the diversity index DIV NWE+WE P which, here again, shows a value of " 0 ".

An analytical examination via correlation according to Pearson confirms the above mentioned assumption that the random sample (= 213 board members) can be divided into three groups. The total random sample shows a high correlation of the three indices with the following values: InEx Norm correlates very significantly with INT Norm with $\mathrm{r}=0.792 * * ; \mathrm{InEx}_{\text {Norm }}$ correlates very significantly with $\mathrm{KP} \mathrm{Norm}$ with $\mathrm{r}=0.721^{* *}$. If the random sample is split up, the group with the 48 foreign board members correlates only weakly with regard to the indices: InEx Norm correlates with INT ${ }_{\text {Norm }}$ only with $r=0.402^{* *}$; nevertheless, the correlation is very significant. Comparable results can be observed for the group without foreign board members that was adjusted for the group of the 66 board members without international experience. The remaining 99 board members $(213-48-66=99)$ likewise showed only weak correlation values between InEx ${ }_{\text {Norm }}$ and INT Norm that were at $r=0.338^{* *}$. The deviation among the indices can be illustrated by histograms with z-transformed values: 

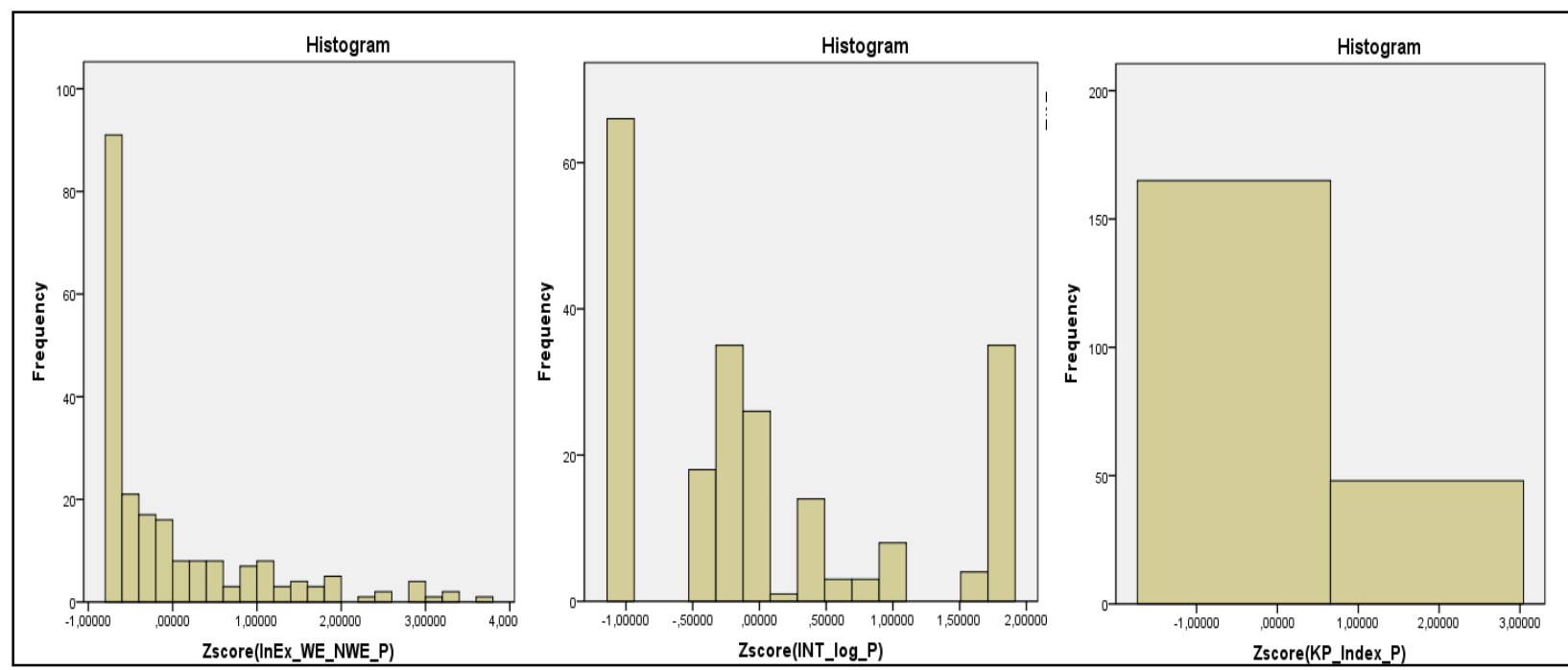

Figure 3: Comparison of different internationality indices related to board members of DAX-listed companies (2010) Note. Own illustration showing the values of 213 board members of DAX-listed companies based on a supplemented / modified data base of the Albstadt-Sigmaringen University (Albstadt-Sigmaringen University, 2011)

The above histograms illustrate the differences in the frequency distribution of the z-transformed values of the individual indices.

\section{DISCUSSION}

Based on the results at hand the following conclusions can be drawn with regard to the hypotheses:

Hypothesis 1: The assessment of the internationality of an individual person or of a management board as a whole on the basis of the nationality only leads to significant distortions, what is illustrated by the index KP Norm or comparable indices. For example, board member no. 92 obtains a KP Norm value of "0" even though this person has collected 32 years of international experience. However, board member no. 92 is a native which accordingly leads to this result. In contrast, board member no. 208 obtains a KP Norm value of „1“, despite the fact that this person's internationality is only due to his or her country of birth which, furthermore, is culturally close to Germany. For the group of the 99 board members with a KP Norm value of " 0 " we obtain the following picture:

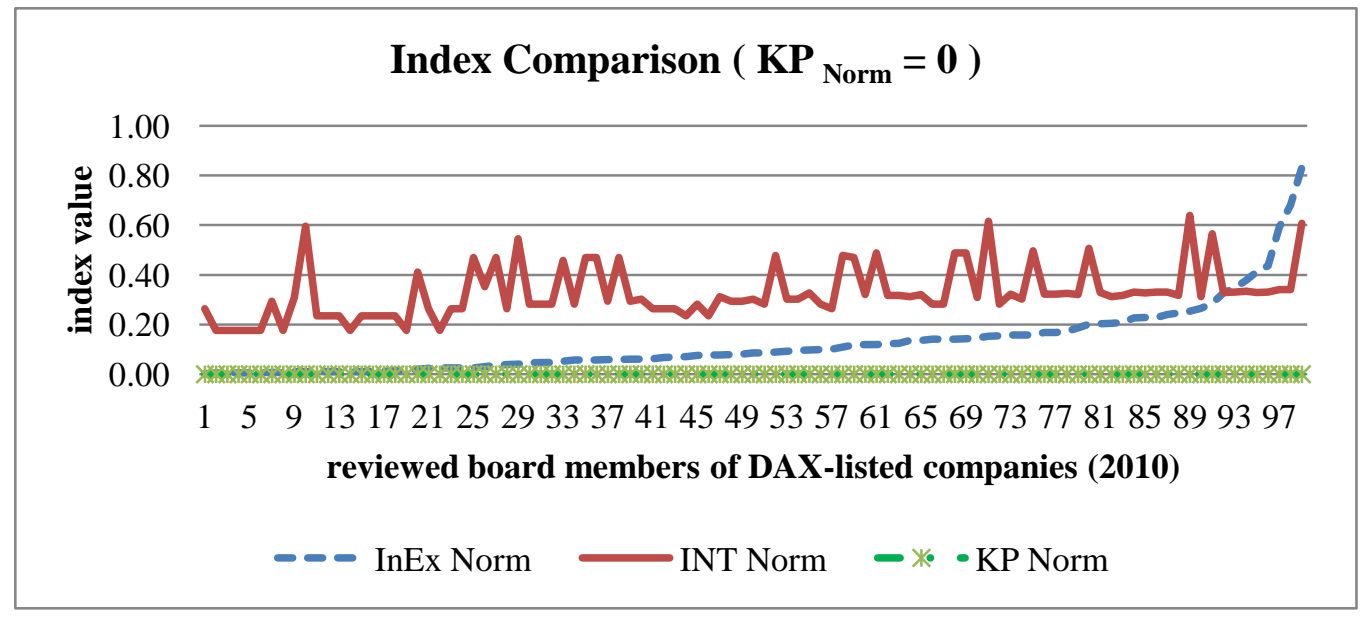

Figure 4: Index comparison between KP Norm, $_{\text {InEx }}$ Norm $_{\text {and INT }}$ Norm

Note. Own illustration showing the values of 99 board members of DAX-listed companies based on the supplemented / modified data base of the Albstadt-Sigmaringen University (Albstadt-Sigmaringen University, 2011) 
The table shows a relevant deviation between the $\mathrm{KP}_{\text {Norm }}$ index on the one hand and the INT ${ }_{\text {Norm }}$ index or the InEx ${ }_{\text {Norm }}$ index, respectively, on the other hand concerning the complete random sample of 99 board members. Due to its structure, the KP ${ }_{\text {Norm }}$ index isn't able to detect existing international work experience, what can lead to misinterpretations. Hypothesis 1 can be regarded as confirmed insofar as the weighting factors CD, SD and FE have contributed to correction.

Hypothesis 2: The comparison of INT ${ }_{\text {Norm }}$ with InEx ${ }_{\text {Norm }}$ shows that the summation of the dimensions $\mathrm{F}$ (nationality), E (education, W (work experience) and A (positions abroad) with 25 to 100 percent inevitably leads to distortions, as already seen at the indices INT $\log$ and INT ${ }_{\text {Norm. }}$. For example, board member no. 208 obtains an INT Norm value of 0.35 and an INT $\log$ P value of 0.25 as 25 percent of the value are reached via nationality. Board member no. 159 obtains an INT Norm value of 0.55 even though this person has only 7 years of international experience (including 3 years of studies) without any mentionable management relevance. Here, InEx Norm delivers a significantly lower value of 0.08 , thus disclosing differentiation potential. This also applies for board member no. 191 who, as a foreigner with 31 years of international work experience, obtains an InEx Norm value of 0.5. However, board member no. 191 doesn't obtain the maximum value of "1" neither, as the international experience was collected in a county that is "culturally close" to Germany. The reasons for the deviations between InEx Norm and INT $_{\text {Norm }}$ are, among other things, the logarithmic function that rates even little experience rather high and the equal weighting of the dimensions. In some cases, for example through the combination of "studies and work experience", this can lead to the result that two of four dimensions at once, that is 50 percent of the index, are taken into consideration for the calculation of the index value. Furthermore, INT $\log$ and INT Norm lack the consideration of cultural differences (CD), of the time dimension (LE / FE) and the aspect of management relevance (SD). Hypothesis 2 can be regarded as confirmed as the distortions of InEx ${ }_{\text {Norm }}$ could be mitigated by taking into account the weighting factors. The table below shows the deviation regarding 48 board members with a maximum KP ${ }_{\text {Norm }}$ value of "1" with simultaneously high INT Norm values. Compared to InEx Norm both indices show extremely high $\left(\mathrm{KP}_{\text {Norm }}\right.$ ) or high (INT ${ }_{\text {Norm}}$ ) values whereas InEx ${ }_{\text {Norm }}$ delivers a quite more differentiated picture.

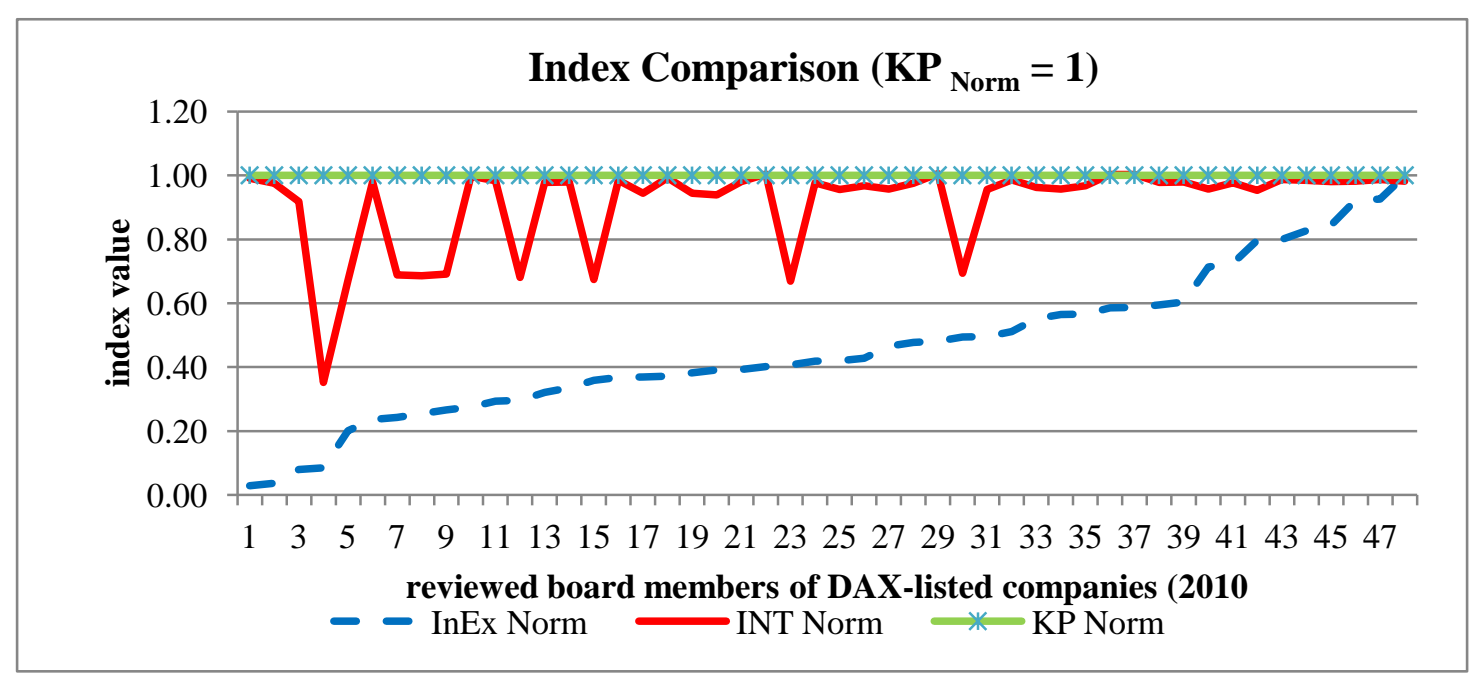

Figure 5: Index comparison between KP Norm, $_{\text {InEx }}$ Norm $_{\text {and INT }}$ Norm

Note. Own illustration showing the values of 48 board members of DAX-listed companies based on the supplemented / modified data base of the Albstadt-Sigmaringen University (Albstadt-Sigmaringen University, 2011)

Hypothesis 3: On examination of the different indices in the framework of the analysis at hand, the example of the board members no. 191 and no. 113 shows that the introduction and implementation of supplementary indices, like for example DIV NWE+WE P, makes sense. Board member no. 113, for example, shows maximum values for all three indices even though this person has collected international experience in his or her home country only and therefore only possesses a "specialized internationality". In contrast, the DIV NWE+WE P index showed a value of „,0“, thus documenting this feature and putting into perspective the other indices. Equal results were detected for board member no. 191. Altogether, hypothesis 3 can be confirmed in view of the annexed data, which means that the 
limitation of the interpretation to one index only can - at least in part - be regarded as deficient. The conclusion could be drawn that the loss of information by concentration on one single index like InEx Norm generally is too high. In other words, the application of sub-indices can be regarded as an alternative, as the illustration below shows:

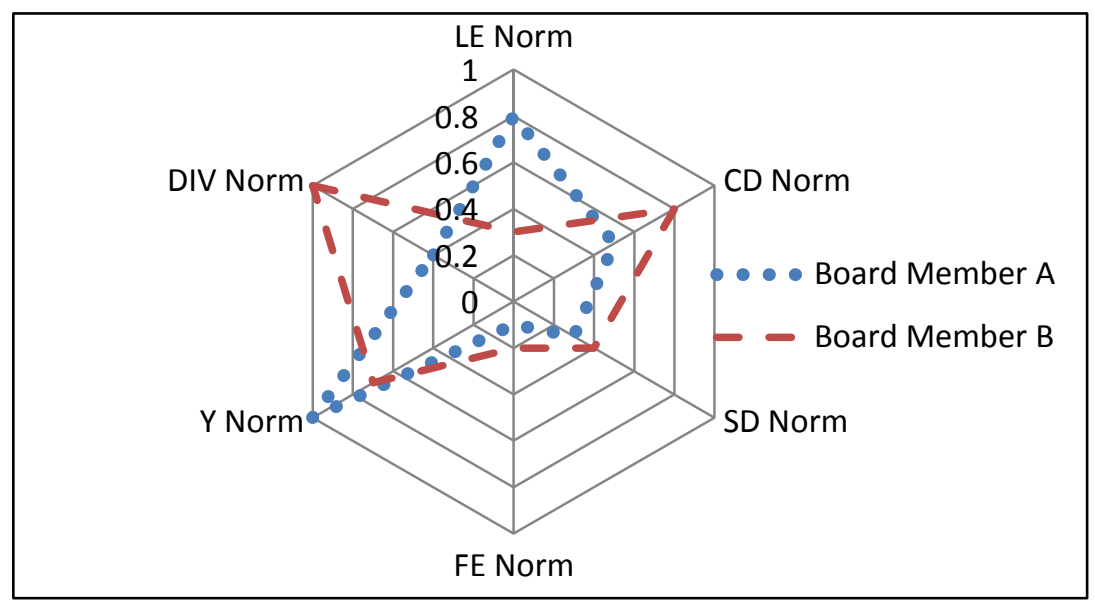

Figure 6: Alternative to the InEx Norm as single indicator

Note. Own illustration based on the supplemented / modified data base of the Albstadt-Sigmaringen University (AlbstadtSigmaringen University, 2011)

A decision about this matter will be the subject of further research and therefore shall only be mentioned as an option at this point.

\section{LIMITATIONS / FUTURE RESEARCH}

The findings and conclusions mentioned above are subject to the following limitations:

(1) The data used in this study is based on CVs that are partly incomplete, ambiguous or even deficient, or allowed for misinterpretations.

(2) The statements about the internationality of a person are based on secondary data only as the collection of primary data, as a rule, is hardly possible. This implies a limited informative value as, for example, information on a person's attitude as defined by the Theory of Planned Behavior (Ajzen, 1985) is missing completely.

(3) As a rule, the formation of indices represents a concentration of information which frequently goes along with the loss of information. Therefore, indices have to be considered to be sometimes limited in their informative value.

(4) InEx NWE+WE P and InEx Norm are based on the assumption that the years spent abroad Y IE can serve as a general measure for international experience. However, this assumption disregards the collected international work experience that may have been gathered without a stay abroad. This simplification had to be made due to the lack of personal data.

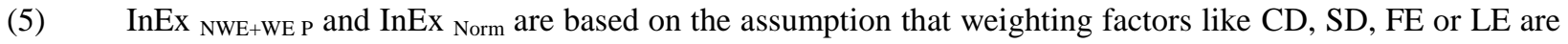
relevant for the assessment of the years spent abroad $\mathrm{Y}_{\mathrm{IE}}$. This number of potential weighting factors could be larger, where necessary. Furthermore, the determination of the weighting factors could be based on other principles, as for example the Kogut-Singh-Index (1988) as well as the cultural dimensions by Hofstede (1980) were often criticized in the past. Recent studies, for example by House et al. (2004) deliver new cultural dimensions that can lead to deviating results. The calculation of the SD value as well as the calculation of the FE and LE values should be further examined with regard to their suitability.

(6) An examination of industry-specific indices remained undone, though it could be expedient for the comparison of management boards as a whole. 
The InEx NWE+WE P and the InEx Norm represent a further development of the existing indices that partly resulted from the need for data simplification and for lack of reliable secondary data. The authors of the simpler

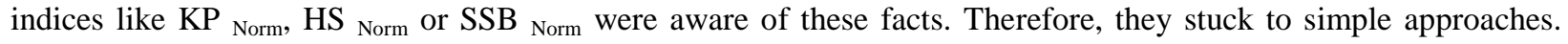
Thus, InEx Norm represents an approach for a more complex index with a possibly higher information value. However, due to its secondary data basis, it will always remain defective and cannot be an adequate substitute for examinations based on primary data.

\section{AUTHOR INFORMATION}

Prof. Dr. Lutz Sommer, Department of Industrial Engineering, Albstadt-Sigmaringen University. This research was supported by the Albstadt-Sigmaringen University, Jakobstrasse 1-6, 72458 Albstadt / Germany. Correspondence concerning this research should be addressed to Lutz Sommer. E-mail: sommer@hs-albsig.de

\section{REFERENCES}

1. Ajzen, I. (1985). From intentions to actions: A theory of planned behavior. In J. Kuhl and J. Beckman (Eds.), Action-Control: From Cognition to Behavior, (pp. 11 - 39). Heidelberg: Springer.

2. Albstadt-Sigmaringen University (ASU) (2011). Forschungs- und Praxisprojekt WS 2011 Studentenprojekt / 4. Semester. Unpublished student project, Department of Business Administration and Engineering, Albstadt-Sigmaringen University, Albstadt, Germany (see also footnote 1).

3. Athanassiou, N., \& Nigh, D. (2002). The Influence of the International Business Experience of the Top Management Team on the Internationalization of the Firm: Social Networks at Work. Management International Review, 42(2), 157-181.

4. Bahrick, H. (1984). Fifty Years of Second Language Attrition - Implications for Programmatic Research. The Modern Language Journal, 68. doi: 10.1111/j.1540-4781.1984.tb01551.x

5. Bahrick, H., Bahrick, L., Bahrick, A., \& Bahrick, P. (1993). Maintenance of Foreign Language Vocabulary and the Spacing Effect. American Psychological Society.

6. Bloodgood, J.M., Sapienza, H.J. \& Almeida, J.G. (1996). The Internationalization of New High-Potential U.S. Ventures: Antecedents and Outcomes. Entrepreneurship Theory and Practice, 20(4), 61-76.

7. Carpenter, M.A. \& J.W. Fredrickson. (2001). Top management teams, global strategic posture, and the moderating role of uncertainty. Academy of Management Journal. 44(3), 533-546. doi: 10.2307/3069368

8. Carpenter, M.A., T.G. Pollock, \& M.M. Leary. (2003). Testing a model of reasoned risk-taking: Governance, the experience or principals and agents, and global strategy in high-technology IPO firms. Strategic Management Journal. 24, 803-820. doi: 10.1002/smj.338

9. Carpenter, M.A. Sanders, W. \& Gregersen, H. (2001). Bundling human capital with organizational context. The impact of international assignment experience on multinational firm performance and CEO pay. Academy of Management Journal, 44(3).

10. Daily, C. M., Certo, S. T., \& Dalton, D.R. (2000). International experience in the executive suite: The path to prosperity? Strategic Management Journal, 21, 515-523. doi: 10.1002/(SICI)1097-

0266(200004)21:4<515::AID-SMJ92>3.0.CO;2-1

11. Egon Zehnder International (2008). Global Board Index. Retrieved from http://www.egonzehnder.com/global/thoughtleadership/hottopic/id/43700172/publication/id/43700177

12. Ghoshal, S. (1987). Global Strategy: An Organizing Framework. Strategic Management Journal, 8(5). doi: $10.1002 /$ smj.4250080503

13. Greve, P., Nielsen, S., \& Ruigrok, W. (2009). Transcending borders with international top management teams: A study of European financial multinational corporations. European Management Journal, 27(3), 213-224 doi: 10.1016/j.emj.2008.10.001

14. Harrison, D.A. \& Klein, K.J. (2007).What's the difference? Diversity constructs as separation, variety, or disparity in organizations. Academy of Management Review, 32, 1199 - 1228. doi: 10.5465/AMR.2007.26586096

15. Hambrick, D.C. \& Mason, P.A. (1984). Upper Echelons. The Organizations as a Reflection of Its Top Managers. Academy of Management Review, 9(2). doi: 10.5465/AMR.1984.4277628 
16. Heidrick \& Struggles Consulting. (2011). Challenging board performance. European Corporate Governance Report 2011. Retrieved from http://www.heidrick.com/PublicationsReports/PublicationsReports/HS EuropeanCorpGovRpt2011.pdf

17. Heijltjes, M. \& Olie, R. \& Glunk, U. (2003). Internationalization of Top Management Teams in Europe. European Management Journal, 21(1), 89 - 97. doi: 10.5465/AMR.2007.26586096

18. Herrmann, P. \& Datta, D.K. (2002). CEO Successor Characteristics and the Choice of Foreign Market Entry Mode. An Empirical Study. Journal of International Business Studies, 33(3). doi: 10.1057/palgrave.jibs.8491031

19. Hofstede, G. (1980). Culture's Consequences - International Differences in Work Related Values. Newbury Park, London, Neu Delhi: Sage Publications.

20. Hofstede, G. (2001). Culture's Consequences - Comparing Values, Behaviors, Institutions and Organizations across Nations. Thousand Oaks, London, Neu Delhi: Sage Publications.

21. Hofstede, G. (2012). Homepage Hofstede; Retrieved from http://www.geert-hofstede.com/

22. House, R,. Hanges, P., Javidan, M., Dorfmann, P. W., \& Gupta, V. (2004). Culture, Leadership and Organizations. The Globe Study of 62 Societies. Thousand Oaks, London, Neu Delhi: Sage Publications.

23. Lee, L. T., \& Sukoco, B., M. (2007). The effects of entrepreneurial orientation and knowledge management capability on organizational effectiveness in Taiwan: The moderating role of social capital. International Journal of Management, 24(3), 549-620.

24. Kogut, B., \& Singh, H. (1988). The effect of national culture on the choice of entry mode. Journal of International Business Studies, 19(3), 411 - 432. doi: 10.1057/palgrave.jibs. 8490394

25. Reuber, R. \& Fischer, E. (1997).The Influence of the Management Team's International Experience on the Internationalizations Behaviors of SMEs. Journal of International Business, 28(4). doi: 10.1057/palgrave.jibs. 8490120

26. Roth, K. (1995). Managing international interdependence. CEO characteristics in a resource-based framework. Academy of Management Journal, 38(1). doi: 10.2307/256733

27. Sambarya, R.B. (1996). Foreign Experience of Top Management Teams and International Diversification Strategies of U.S. Multinational Corporations. Strategic Management Journal, 17(9).

28. Schmid, S. \& Daniel, A. (2006). Measuring Board Internationalization - Towards a More Holistic Approach ( ESCP-EAP Working Paper, No. 21). Berlin: European School of Management.

29. Schmid, S. \& Kretschmer, K. (2005). How International are German Supervisory Boards? - An Exploratory Study. Berlin: ESCP-EAP.

30. Simon Kucher \& Partners Strategy \& Marketing Consultants (2011). DAX-Führungsspitzen: Sehr international, aber kaum weiblich, Pressemitteilung vom 28. Juli 2011. Retrieved from http://www.ptmagazin.de/newsartikel/archive/2011/august/10/article/dax-fuehrungsspitzen-sehr-international-aber-kaumweiblich.html

31. Simon Kucher \& Partners Strategy \& Marketing Consultans (2005-2011). Webpage. Retrieved from http://www.simon-kucher.com/

32. Simpson, E. H. (1949). Measurement of diversity. Nature, 163, 688. doi: 10.1038/163688a0

33. Sommer, L. (2009). Degree of Internationalization - A Multidimensional Challenge. Journal of Applied Business Research, 25 (3), 93-106

34. Sommer, L. (2012). The Measurement of International Experience as a Dimension of Board Indices: Concept for an Improvement. International Journal of Business Administration, 3, 2-19. doi: 10.5430/ijba.v3n4p2

35. Spencer Stuart (2010). Der Spencer Stuart Board Index - Deutschland 2010. Retrieved from http://www.spencerstuart.com//global

36. Spencer Stuart (2011). Spencer Stuart Board Index. Retrieved from http://www.spencerstuart.com//global

37. Sullivan, D. (1994). The "Threshold of Internationalization". Replication, extension, and reinterpretation. Management International Review, 34(2), 165 - 186.

38. Takeuchi, R., Tesluk, P.E., Yun, S., \& Lepak, D. (2005). An integrative view of international experiences: An empirical examination. Academy of Management Journal, 48, 85-100. doi: 10.5465/AMJ.2005.15993143

39. Tihany, L., Ellstrand, A. E., Daily, C. M., \& Dalton, D. R. (2000). Composition of the Top Management Team and Firm International Diversification. Journal of Management, 26(6), 1157. 
40. Tushman, M.L. \& Nadler, D.A. (1978). Information Processing as an Integrating Concept in Organizational Design. Academy of Management Review, 3. doi: 10.5465/AMR.1978.4305791

41. Wally, S. \& Becerra, M. (2001). Top management team characteristics and strategic changes in international diversification: The case of U.S. multinationals in the European Community. Group and Organization Management, 26, 165-188. doi: 10.1177/1059601101262003

42. Willcocks, L. (2011). Machiavelli, management and outsourcing: still on the learning curve. Strategic Outsourcing: An International Journal, 4(1), 5-12

43. Wixted, J., \& Ebbesen, E. (1991). On the form of forgetting. American Psychological Society, 2(6), 409415 .

\section{FOOTNOTES}

1. The data are from an unpublished student research project. They were collected by the students of Business Administration and Engineering Belhid Bajra, Hon Kit Chow, Christoph Heller, Martina Pfister, Philipp Pfister and Sing Yee Poh. Modified and used with permission.

\section{APPENDICES}

\section{Annex 1:}

1. Homepages Company

2. Forbes

3. Who is who

4. Newsweek

5. Financial Times

6. www.wsj.com

7. www.focus.de

8. http://www.bloomberg.com/

(http://investing.businessweek.com/research/company/overview/overview.asp)

9. http://www.edubourse.com/guide/biographies.php (no date)

10. http://www.karrierefuehrer.de/manager/ (no date)

11. Manager Magazine (2011) Galerie der Titelträger. Available at: http://www.manager-magazin.de/unternehmen/karriere/0,2828,167345,00.html

12. http://www.munzinger.de (2011)

13. http://www.wienerborse.at/about/press/vorstand.html (2011)

14. $\quad$ http://www.annualreports.com (2011)

15. $\quad$ www.reuters.com (no date)

16. http://www.wiwo.de/koepfe-der-wirtschaft/ (2011)

17. Les Barons de la Bourse (no date) Available at: http://www.zonebourse.com/barons-bourse/biographie/

18. http://www.iqc.ca/people/person.php?id=313

19. http://www.biography.com/people/bill-gates-9307520?page=1

20. http://www.achievement.org/autodoc/halls/bus

21. http://www.woopidoo.com/biography/index.htm

22. http://www.handelsblatt.com/unternehmen/management/koepfe/ (2011)

23. http://www.dgap.de/dgap/static/companies 
Annex 2: Comparison of the internationality indices of 213 board members of 30 DAX-listed companies (2010)

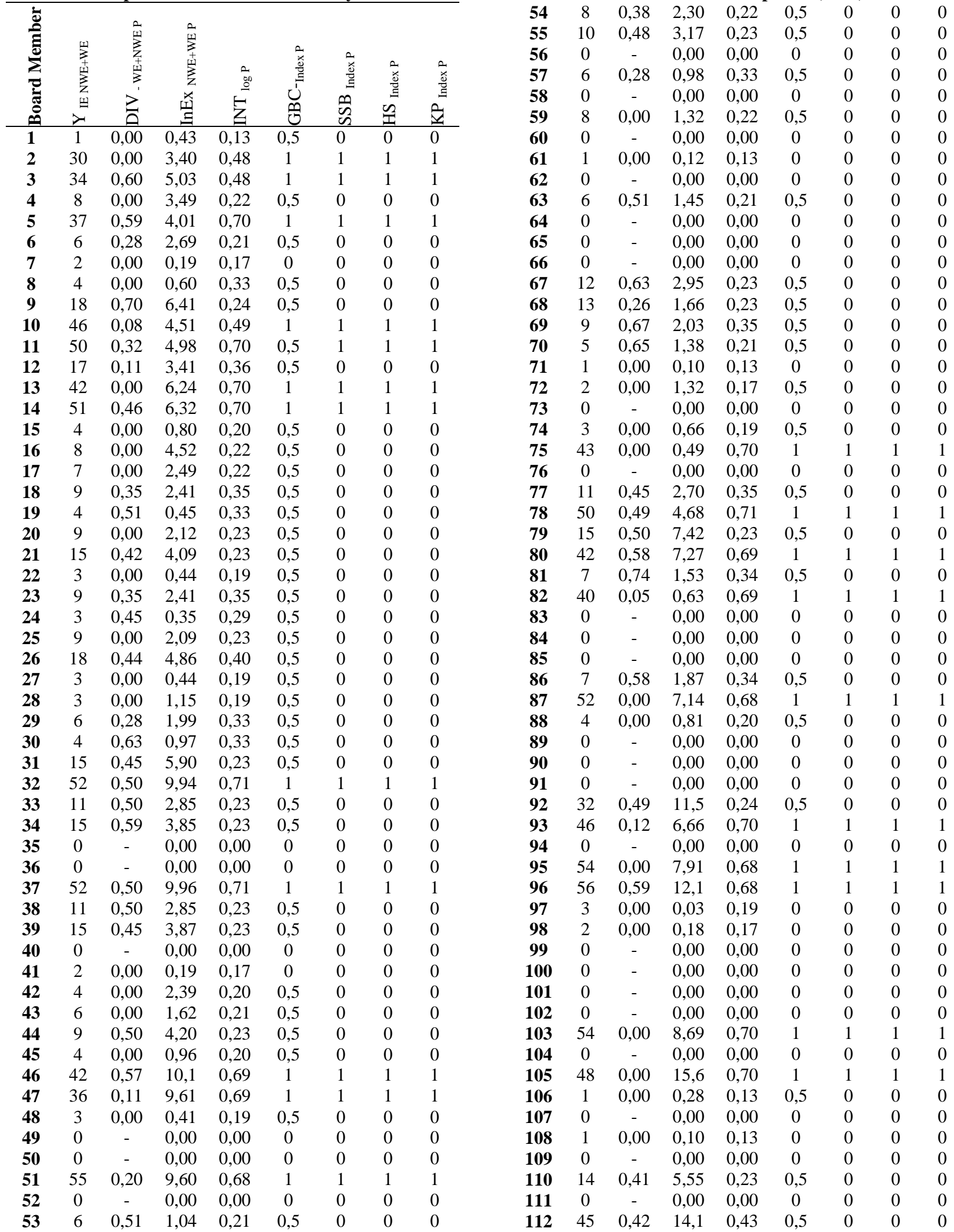




\begin{tabular}{|c|c|c|c|c|c|c|c|c|}
\hline 113 & 47 & 0,00 & 16,9 & 0,70 & 1 & 1 & 1 & 1 \\
\hline 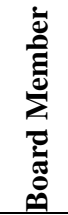 & 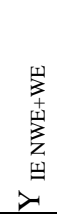 & 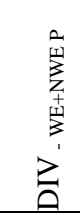 & 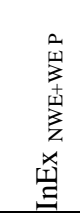 & 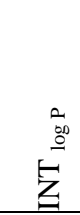 & نी & 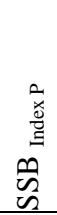 & 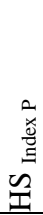 & 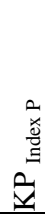 \\
\hline 114 & 0 & - & 0,00 & 0,00 & 0 & 0 & 0 & 0 \\
\hline 115 & 2 & 0,00 & 0,22 & 0,17 & 0 & 0 & 0 & 0 \\
\hline 116 & 0 & - & 0,00 & 0,00 & 0 & 0 & 0 & 0 \\
\hline 117 & 4 & 0,63 & 1,29 & 0,20 & 0,5 & 0 & 0 & 0 \\
\hline 118 & 42 & 0,00 & 4,11 & 0,49 & 1 & 1 & 1 & 1 \\
\hline 119 & 53 & 0,00 & 14,0 & 0,70 & 1 & 1 & 1 & 1 \\
\hline 120 & 53 & 0,00 & 8,39 & 0,49 & 1 & 1 & 1 & 1 \\
\hline 121 & 59 & 0,00 & 8,17 & 0,71 & 1 & 1 & 1 & 1 \\
\hline 122 & 37 & 0,49 & 6,26 & 0,67 & 1 & 1 & 1 & 1 \\
\hline 123 & 1 & 0,00 & 0,13 & 0,13 & 0 & 0 & 0 & 0 \\
\hline 124 & 0 & - & 0,00 & 0,00 & 0 & 0 & 0 & 0 \\
\hline 125 & 6 & 0,28 & 1,01 & 0,33 & 0,5 & 0 & 0 & 0 \\
\hline 126 & 11 & 0,00 & 2,67 & 0,23 & 0,5 & 0 & 0 & 0 \\
\hline 127 & 0 & - & 0,00 & 0,00 & 0 & 0 & 0 & 0 \\
\hline 128 & 0 & - & 0,00 & 0,00 & 0 & 0 & 0 & 0 \\
\hline 129 & 30 & 0,29 & 6,65 & 0,67 & 1 & 1 & 1 & 1 \\
\hline 130 & 0 & - & 0,00 & 0,00 & 0 & 0 & 0 & 0 \\
\hline 131 & 40 & 0,00 & 8,10 & 0,69 & 1 & 1 & 1 & 1 \\
\hline 132 & 43 & 0,00 & 10,2 & 0,70 & 1 & 1 & 1 & 1 \\
\hline 133 & 1 & 0,00 & 0,10 & 0,13 & 0 & 0 & 0 & 0 \\
\hline 134 & 4 & 0,00 & 0,79 & 0,20 & 0,5 & 0 & 0 & 0 \\
\hline 135 & 0 & - & 0,00 & 0,00 & 0 & 0 & 0 & 0 \\
\hline 136 & 0 & - & 0,00 & 0,00 & 0 & 0 & 0 & 0 \\
\hline 137 & 2 & 0,51 & 0,51 & 0,25 & 0,5 & 0 & 0 & 0 \\
\hline 138 & 0 & - & 0,00 & 0,00 & 0 & 0 & 0 & 0 \\
\hline 139 & 20 & 0,50 & 4,30 & 0,45 & 0,5 & 0 & 0 & 0 \\
\hline 140 & 0 & - & 0,00 & 0,00 & 0 & 0 & 0 & 0 \\
\hline 141 & 0 & - & 0,00 & 0,00 & 0 & 0 & 0 & 0 \\
\hline 142 & 1 & 0,00 & 0,10 & 0,13 & 0 & 0 & 0 & 0 \\
\hline 143 & 0 & - & 0,00 & 0,00 & 0 & 0 & 0 & 0 \\
\hline 144 & 0 & - & 0,00 & 0,00 & 0 & 0 & 0 & 0 \\
\hline 145 & 6 & 0,45 & 1,57 & 0,21 & 0,5 & 0 & 0 & 0 \\
\hline 146 & 29 & 0,00 & 1,34 & 0,65 & 1 & 1 & 1 & 1 \\
\hline 147 & 47 & 0,27 & 13,5 & 0,68 & 1 & 1 & 1 & 1 \\
\hline 148 & 5 & 0,00 & 0,89 & 0,33 & 0,5 & 0 & 0 & 0 \\
\hline 149 & 0 & - & 0,00 & 0,00 & 0 & 0 & 0 & 0 \\
\hline 150 & 46 & 0,12 & 6,82 & 0,71 & 1 & 1 & 1 & 1 \\
\hline 151 & 46 & 0,37 & 14,3 & 0,70 & 1 & 1 & 1 & 1 \\
\hline 152 & 16 & 0,43 & 2,60 & 0,44 & 0,5 & 0 & 0 & 0 \\
\hline 153 & 9 & 0,35 & 3,53 & 0,23 & 0,5 & 0 & 0 & 0 \\
\hline 154 & 0 & - & 0,00 & 0,00 & 0 & 0 & 0 & 0 \\
\hline 155 & 57 & 0,36 & 13,5 & 0,70 & 1 & 1 & 1 & 1 \\
\hline 156 & 10 & 0,00 & 2,03 & 0,23 & 0,5 & 0 & 0 & 0 \\
\hline 157 & 3 & 0,00 & 1,72 & 0,19 & 0,5 & 0 & 0 & 0 \\
\hline 158 & 4 & 0,00 & 1,68 & 0,20 & 0,5 & 0 & 0 & 0 \\
\hline 159 & 7 & 0,49 & 0,69 & 0,39 & 0,5 & 0 & 0 & 0 \\
\hline 160 & 4 & 0,00 & 2,64 & 0,20 & 0,5 & 0 & 0 & 0 \\
\hline 161 & 2 & 0,00 & 0,19 & 0,17 & 0 & 0 & 0 & 0 \\
\hline 162 & 13 & 0,48 & 3,87 & 0,23 & 0,5 & 0 & 0 & 0 \\
\hline 163 & 0 & - & 0,00 & 0,00 & 0 & 0 & 0 & 0 \\
\hline 164 & 0 & - & 0,00 & 0,00 & 0 & 0 & 0 & 0 \\
\hline 165 & 4 & 0,00 & 1,46 & 0,20 & 0,5 & 0 & 0 & 0 \\
\hline
\end{tabular}

\begin{tabular}{ccccccccc}
$\mathbf{1 6 6}$ & 14 & 0,72 & 7,00 & 0,23 & 0,5 & 0 & 0 & 0 \\
$\mathbf{1 6 7}$ & 41 & 0,00 & 12,3 & 0,69 & 1 & 1 & 1 & 1 \\
$\mathbf{1 6 8}$ & 57 & 0,00 & 15,7 & 0,70 & 1 & 1 & 1 & 1 \\
$\mathbf{1 6 9}$ & 3 & 0,00 & 1,19 & 0,19 & 0,5 & 0 & 0 & 0 \\
$\mathbf{1 7 0}$ & 1 & 0,00 & 0,19 & 0,13 & 0,5 & 0 & 0 & 0 \\
$\mathbf{1 7 1}$ & 0 & - & 0,00 & 0,00 & 0 & 0 & 0 & 0 \\
$\mathbf{1 7 2}$ & 0 & - & 0,00 & 0,00 & 0 & 0 & 0 & 0 \\
$\mathbf{1 7 3}$ & 2 & 0,00 & 0,20 & 0,17 & 0 & 0 & 0 & 0 \\
$\mathbf{1 7 4}$ & 5 & 0,00 & 0,13 & 0,21 & 0,5 & 0 & 0 & 0 \\
$\mathbf{1 7 5}$ & 29 & 0,61 & 10,0 & 0,24 & 0,5 & 0 & 0 & 0 \\
$\mathbf{1 7 6}$ & 5 & 0,00 & 1,04 & 0,21 & 0,5 & 0 & 0 & 0 \\
$\mathbf{1 7 7}$ & 11 & 0,00 & 0,18 & 0,42 & 0,5 & 0 & 0 & 0 \\
$\mathbf{1 7 8}$ & 29 & 0,00 & 6,91 & 0,48 & 1 & 1 & 1 & 1 \\
$\mathbf{1 7 9}$ & 0 & - & 0,00 & 0,00 & 0 & 0 & 0 & 0 \\
$\mathbf{1 8 0}$ & 0 & - & 0,00 & 0,00 & 0 & 0 & 0 & 0 \\
$\mathbf{1 8 1}$ & 0 & - & 0,00 & 0,00 & 0 & 0 & 0 & 0 \\
$\mathbf{1 8 2}$ & 10 & 0,00 & 2,31 & 0,23 & 0,5 & 0 & 0 & 0 \\
$\mathbf{1 8 3}$ & 42 & 0,00 & 5,44 & 0,69 & 1 & 1 & 1 & 1 \\
$\mathbf{1 8 4}$ & 34 & 0,16 & 9,38 & 0,68 & 1 & 1 & 1 & 1 \\
$\mathbf{1 8 5}$ & 0 & - & 0,00 & 0,00 & 0 & 0 & 0 & 0 \\
$\mathbf{1 8 6}$ & 0 & - & 0,00 & 0,00 & 0 & 0 & 0 & 0 \\
$\mathbf{1 8 7}$ & 0 & - & 0,00 & 0,00 & 0 & 0 & 0 & 0 \\
$\mathbf{1 8 8}$ & 37 & 0,58 & 6,50 & 0,67 & 1 & 1 & 1 & 1 \\
$\mathbf{1 8 9}$ & 43 & 0,13 & 5,69 & 0,70 & 1 & 1 & 1 & 1 \\
$\mathbf{1 9 0}$ & 2 & 0,00 & 1,20 & 0,17 & 0,5 & 0 & 0 & 0 \\
$\mathbf{1 9 1}$ & 51 & 0,00 & 8,42 & 0,68 & 1 & 1 & 1 & 1 \\
$\mathbf{1 9 2}$ & 14 & 0,00 & 3,45 & 0,23 & 0,5 & 0 & 0 & 0 \\
$\mathbf{1 9 3}$ & 5 & 0,32 & 1,35 & 0,21 & 0,5 & 0 & 0 & 0 \\
$\mathbf{1 9 4}$ & 39 & 0,39 & 4,32 & 0,49 & 1 & 1 & 1 & 1 \\
$\mathbf{1 9 5}$ & 0 & - & 0,00 & 0,00 & 0 & 0 & 0 & 0 \\
$\mathbf{1 9 6}$ & 4 & 0,00 & 2,39 & 0,20 & 0,5 & 0 & 0 & 0 \\
$\mathbf{1 9 7}$ & 2 & 0,00 & 0,24 & 0,17 & 0,5 & 0 & 0 & 0 \\
$\mathbf{1 9 8}$ & 5 & 0,48 & 1,01 & 0,21 & 0,5 & 0 & 0 & 0 \\
$\mathbf{1 9 9}$ & 0 & - & 0,00 & 0,00 & 0 & 0 & 0 & 0 \\
$\mathbf{2 0 0}$ & 0 & - & 0,00 & 0,00 & 0 & 0 & 0 & 0 \\
$\mathbf{2 0 1}$ & 0 & - & 0,00 & 0,00 & 0 & 0 & 0 & 0 \\
$\mathbf{2 0 2}$ & 0 & - & 0,00 & 0,00 & 0 & 0 & 0 & 0 \\
$\mathbf{2 0 3}$ & 7 & 0,00 & 0,17 & 0,22 & 0,5 & 0 & 0 & 0 \\
$\mathbf{2 0 4}$ & 0 & - & 0,00 & 0,00 & 0 & 0 & 0 & 0 \\
$\mathbf{2 0 5}$ & 0 & - & 0,00 & 0,00 & 0 & 0 & 0 & 0 \\
$\mathbf{2 0 6}$ & 3 & 0,00 & 1,06 & 0,19 & 0,5 & 0 & 0 & 0 \\
$\mathbf{2 0 7}$ & 0 & - & 0,00 & 0,00 & 0 & 0 & 0 & 0 \\
$\mathbf{2 0 8}$ & 20 & 0,00 & 1,43 & 0,25 & 0,5 & 1 & 1 & 1 \\
$\mathbf{2 0 9}$ & 31 & 0,43 & 6,09 & 0,48 & 1 & 1 & 1 & 1 \\
$\mathbf{2 1 0}$ & 0 & - & 0,00 & 0,00 & 0 & 0 & 0 & 0 \\
& 0,33 & 7,10 & 0,69 & 1 & 1 & 1 & 1 \\
$\mathbf{1 3}$ & - & 0,00 & 0,00 & 0 & 0 & 0 & 0 \\
$\mathbf{1 0}$ & 0,00 & 0,00 & 0 & 0 & 0 & 0 \\
\hline
\end{tabular}

Note: Source: Own illustration based on the supplemented / modified data base of a student research project at the Albstadt-Sigmaringen University (Albstadt-Sigmaringen University, 2011) 
NOTES 